\title{
Manifiesto Tassili: una galería en el albor de la modernidad
}

\author{
Juan Carlos Aparicio Vega \\ Universidad de Oviedo. Departamento de Historia del Arte y Musicología \\ apariciojuan@uniovi.es
}

Recepción: 07/04/2020, Aceptación: 28/09/2020, Publicación: 28/12/2020

\begin{abstract}
RESUMEN
Tras un período de tanteo en el incipiente circuito de las galerías de arte moderno a lo largo de los años cincuenta y sesenta, sería con el arranque de la década siguiente cuando se multiplicase el número de establecimientos dedicados a presentar el arte nuevo en España, adelantándose a los cambios políticos y sociales acontecidos poco tiempo después. En este ensayo abordamos el primer estudio monográfico completo acerca de la galería Tassili de Oviedo, destacada firma que elevó considerablemente el nivel de las propuestas y sobresalió no solo por la calidad de su casi centenar y medio de exposiciones, sino también por sus instalaciones y por la coherente línea de trabajo desarrollada durante cerca de diez años. Este local llegó a congregar y hasta a identificar a la comunidad artística más vanguardista de su territorio, representada por el grupo experimental Astur 7I, que incluso se reunía periódicamente en la sala. Para la realización de esta investigación se ha contado con fuentes de información excepcionales y muy variadas, incluido el archivo de la galería, además del propio testimonio de su promotor, José Antonio Fernández-Castañón, quien reflejó en su forma de trabajar su inicial perfil como crítico comprometido con la difusión y la democratización del arte de su tiempo. La galería es, sin duda, una de las empresas más recordadas de la modernidad plástica asturiana y aún carecía de un estudio a fondo que la ayudara a situarse en la creciente historiografía sobre el comercio artístico y sus intermediarios.
\end{abstract}

Palabras clave:

Tassili; galería de arte; Oviedo; José Antonio Fernández-Castañón; arte contemporáneo; comercio artístico; Astur 71; grupo artístico; José María Navascués

\section{ABStRact}

\section{Tassili Manifesto: An art gallery at the dawn of modernity}

After a period of trial and error in the emerging circuit of modern art galleries throughout the I950s and I960s, the start of the following decade witnessed the number of establishments dedicated to presenting contemporary art in Spain multiply, thus anticipating the political and social changes that took place shortly thereafter. This work undertakes the first complete monographic study of the Tassili Art Gallery in Oviedo (Asturias); a prominent firm that raised the level of the art proposals considerably and stood out not only for the quality of its almost I 50 exhibitions, but also for its facilities and for the consistent line of work developed over nearly ten years. This venue brought together and identified the most avant-garde artistic community in its territory, represented by the experimental art group Astur 7I - which even met regularly in the art gallery's hall. Extraordinary and very diverse sources of information have been taken into account in order to carry out this research, including the art gallery's archive, as well as the very testimony of its promoter, José Antonio Fernández-Castañón, whose work reflected his initial career as an art critic committed to the dissemination and democratization of the art of his time. This art gallery is, without a doubt, one of the most remembered companies in the Asturian fine arts modernity. However, it was lacking an in-depth study to help it place itself in the growing historiography about the art trade and art intermediaries.

Keywords:

Tassili; art gallery; Oviedo; José Antonio Fernández-Castañón; contemporary art; art trade; Astur 71; art group; José María Navascués 
$\mathrm{E}$ 1 crecimiento del sector de las galerías de arte, iniciado en Catalunya ${ }^{1}$ en I 870 con la pionera Sala Parès ${ }^{2}$, no tuvo un verdadero desarrollo extendido a todo el territorio estatal de forma generalizada hasta justo un siglo después, ya claramente atento a las artes vivas ${ }^{3}$. En ese largo período de cien años han sido muchas las iniciativas de interés distribuidas por varios focos que poco a poco van siendo objeto de estudios monográficos y de conjunto.

Tras el quiebro provocado por la guerra civil y el consiguiente cambio de paradigma político y social impuesto por la dictadura, que interrumpió el desarrollo del arte nuevo ${ }^{4}$, pleno de talentos y espejo de una contenida idea de modernidad, se produjo una lenta recuperación del sector del comercio artístico. No escasearon los negocios deinterés que, a cuentagotas, iban repercutiendo de forma clandestina en la construcción, ex novo, de un circuito de galerías en mitad de un auténtico desierto cultural que se prolongó durante cuatro décadas. Sería interminable la nómina de establecimientos que marcaron el camino desde muy diferentes focos liderados por lo acontecido en Barcelona y Madrid. En la capital catalana la prolífica lista de establecimientos existentes, algunos obligados incluso a cambiar de nombre para continuar su actividad, incluía antiguas firmas tan reconocidas como Sala Gaspar (I907) y Syra (193I), siendo además refundadas las Galerías Layetanas (1945) y constituidas otras sociedades de éxito como El Jardín ${ }^{5}$ (1944), que mantuvieron el buen nivel de las propuestas. Mientras, en Madrid ${ }^{6}$ el camino lo abrieron mueblerías como la de Biosca ${ }^{7}$ (1940), quien trasladó el modelo aprendido con el mueblista y pintor Badrinas, y Estilo ${ }^{8}$ (1943), ambas amparadas por el régimen franquista. Además, apoyadas en negocios de libros, fueron sobresalientes las trayectorias de las firmas Clan', a cargo de Tomás Seral, y Buchholz ${ }^{10}$, ambas abiertas en el año 1945.

Después de esos prolegómenos, en la década siguiente se sumaron otras empresas que acusaron, en la mayor parte de los casos, la precariedad del sector, entre las que cabe nombrar para el ámbito madrileño la sala dirigida por Carmen Abril ${ }^{11}$, que tomó el relevo de la librería Clan en la década de los años cincuenta, y Nebli1'12 (1958), con una mayor ambición programática.

Esa estela solidificó durante los años siguientes, en que se fundaron las galerías René Metras y Belarte $^{13}$ ( I 962), Juana Mordó ${ }^{14}$, Edurne ${ }^{15}$ y Bene$\operatorname{det}^{16}$ (1964), Theo ${ }^{17}$ y Seiquer ${ }^{18}$ (1966) o, ya en las puertas del período que nos ocupa, $\operatorname{Sen}^{19}$ y Egam ${ }^{20}$ (1969), entre otras.

Mientras, en el territorio asturiano, objeto de nuestro estudio, el paupérrimo panorama de posguerra había dado un salto cualitativo con el establecimiento de un moderno centro cultural implantado con los salones de la Obra Social y Cultural de la Caja de Ahorros de Asturias, donde también se cerraban ventas que culminaron un proceso de recuperación lento jalonado por algunos eventos relevantes y abonado por la impecable labor de algunos grupos de trabajo, como el de la Tertulia Naranco ${ }^{21}$ (Oviedo, I953), de la que saldrá la figura del galerista Felipe Santullano, activo en el Madrid de la década de los años sesenta. Las salas Altamira y Cristamol ${ }^{22}$ (1958) fueron un prolegómeno de calidad secundado por Carmen Benedet, que abrió su propia galería, diseñada por Joaquín Vaquero, tras asociarse con Juana Mordó en 1964, el mismo año en que empezó a programar en Gijón el marchante Eduardo Vigil en Atalaya ${ }^{23}$.

El trabajo de estas pocas empresas, auxiliadas por otros negocios principales (venta de regalos, marcos y molduras, papelería o librería), fue determinante y contribuyó a crear un clima propicio 
en un circuito pequeño que comenzaba a tener interés y que preludiaba incluso una diversificación del sector poco tiempo después.

Sin embargo, una de las cuestiones reseñables para comprender la situación en Asturias es la carencia de estructuras públicas ${ }^{24}$ sólidas interesadas por coleccionar y, por tanto, por incrementar la adquisición de obras de arte contemporáneo. El año I97I abrió sus puertas tímidamente el Museo Casa Natal de Jovellanos ${ }^{25}$ en la ciudad de Gijón, institución de lentísimo crecimiento, más atenta en la década de los años setenta a mejorar la representación de pintura antigua a través de compras puntuales en establecimientos especializados. Entretanto, en Oviedo, el museo de pintura permanecía durmiente en el Palacio del Gobierno de la Corporación Provincial, que ocasionalmente efectuaba compras destinadas a un nuevo equipamiento que tendría que esperar su turno, pues se primó la refundación del Museo Arqueológico. Así, pocos meses antes de la apertura de la firma que centra nuestro estudio, se constituyó el Centro Provincial de Bellas Artes (1969), con sede en el Palacio de Velarde desde dos años más tarde, si bien no se conseguiría poner en marcha hasta $1980^{26}$, precisamente bajo la dirección de José Antonio Fernández-Castañón, el propietario de la galería Tassili, que cerraría pocos meses antes.

En nuestro trabajo ofrecemos una completa revisión ${ }^{27}$ de la historia y de la actividad de la firma de Fernández Castañón, poniendo de manifiesto su cuidado ideario estético y su entreverada relación con el ambiente artístico local y nacional, que se sentía aceptado en una sala privada por primera vez en Asturias.

\section{La galería Tassili: apertura, local e instalación}

Tassili abrió sus puertas en el número 5 de la calle Uría de Oviedo. Ocupaba el entresuelo ${ }^{28}$ de un edificio de viviendas de gran programa que había ideado el año 1935 Enrique Rodríguez Bustelo $(\text { I } 885-1983)^{29}$.

La galería recibió el nombre de la meseta argelina en que se encuentran los conocidos relieves y pinturas rupestres prehistóricos. De este modo, dicha denominación alusiva al macizo sahariano de Tassili N'Ajjer enlaza con el caso gijonés de Altamira, uno de los primeros lugares del arte prehistórico $^{30}$.

José Antonio Fernández-Castañón Carrasco (Madrid, 1939) dirigió el establecimiento desde el I de abril de i 970 y lo clausuró en el mes de junio de $1979^{31}$. Previamente, se había licenciado en Derecho en la Universidad de Oviedo y completado sus estudios en la Escuela Oficial de Periodismo de Madrid, siendo lector de español en varias universidades europeas en la década de los años sesenta (Carcasonne, Stocke-on-Trent). Además, sus tempranas inquietudes le llevaron a desempeñar labores de redactor en las páginas culturales del diario ovetense Región y en la reputada revista Asturias Semanal, entre otros medios ${ }^{32}$.

El cierre del negocio fue debido a que su promotor pasó a dirigir el nuevo museo provincial. Anteriormente, había ejercido como redactor de arte $^{33}$ en la publicación divulgativa Asturias Semanal ${ }^{34}$, actividad en la que cesó justo cuando comenzó su dedicación en el comercio artístico. Desde las páginas del semanario referido el galerista defendía la democratización del arte, limitada en aquel tiempo en mayor medida a una «minoría adinerada», planteaba la extensión de la obra múltiple ${ }^{35} \mathrm{y}$ demostraba su interés por la experimentación ${ }^{36}$. Además, informaba no solo de lo que ocurría en nuestro territorio, sino también en el ámbito nacional e internacional, tratando de contextualizarlo adecuadamente. El propio director de Tassili días antes de abrir su espacio reflexionaba sobre la figura del marchante y acerca del arte como «artículo normal de consumo» ${ }^{37}$.

Se trataba de un local que por vez primera no dependía de un negocio principal que posibilitara la exhibición de propuestas contemporáneas. Por tanto, Castañón estableció una auténtica galería de arte del presente y planificó todo lo relacionado con su gestión de un modo independiente, si bien contaba con una gran ventaja ${ }^{38}$ : disponía de un piso en propiedad en el centro de Oviedo.

Toda una generación de artistas se identificó con la firma, que avanzó en la consideración de la profesión de galerista en la región. Esto también era una novedad y en ningún caso anterior (Altamira, Cristamol, Atalaya y Benedet) se había logrado una plena identificación del intermediario con sus representados.

La construcción del edificio de viviendas de alquiler, con fachada ${ }^{39}$ a las calles de Uría y González del Valle, fue encargada por Encarnación Menéndez Grande ${ }^{40}$, que, debido a la guerra, no concluyó hasta $\mathrm{I} 94 \mathrm{I}^{41}$. La nueva casa cuenta con cinco plantas que contienen una vivienda por nivel, además de un ático dividido en dos apartamentos más (uno para portería) ${ }^{42}$.

$\mathrm{El} 7$ de marzo de 1970 fue expedida la licencia de apertura ${ }^{43}$ de la sala de arte, tras «habilitar tres de sus piezas de dicha vivienda (también hogar familiar)» para la instalación de una «galería de exposiciones». Así, se adaptó parte de una enorme residencia de lujo para el fin expuesto. Se partía de un programa que incluía hasta cinco dormitorios, entre los que sobresalía el principal con su propio guardarropa, un cuarto de servicio, una cocina que se completaba con office e incluso una fresquera, baño y dos aseos (uno para los empleados del hogar), comedor, una sala amplia y un despa- 

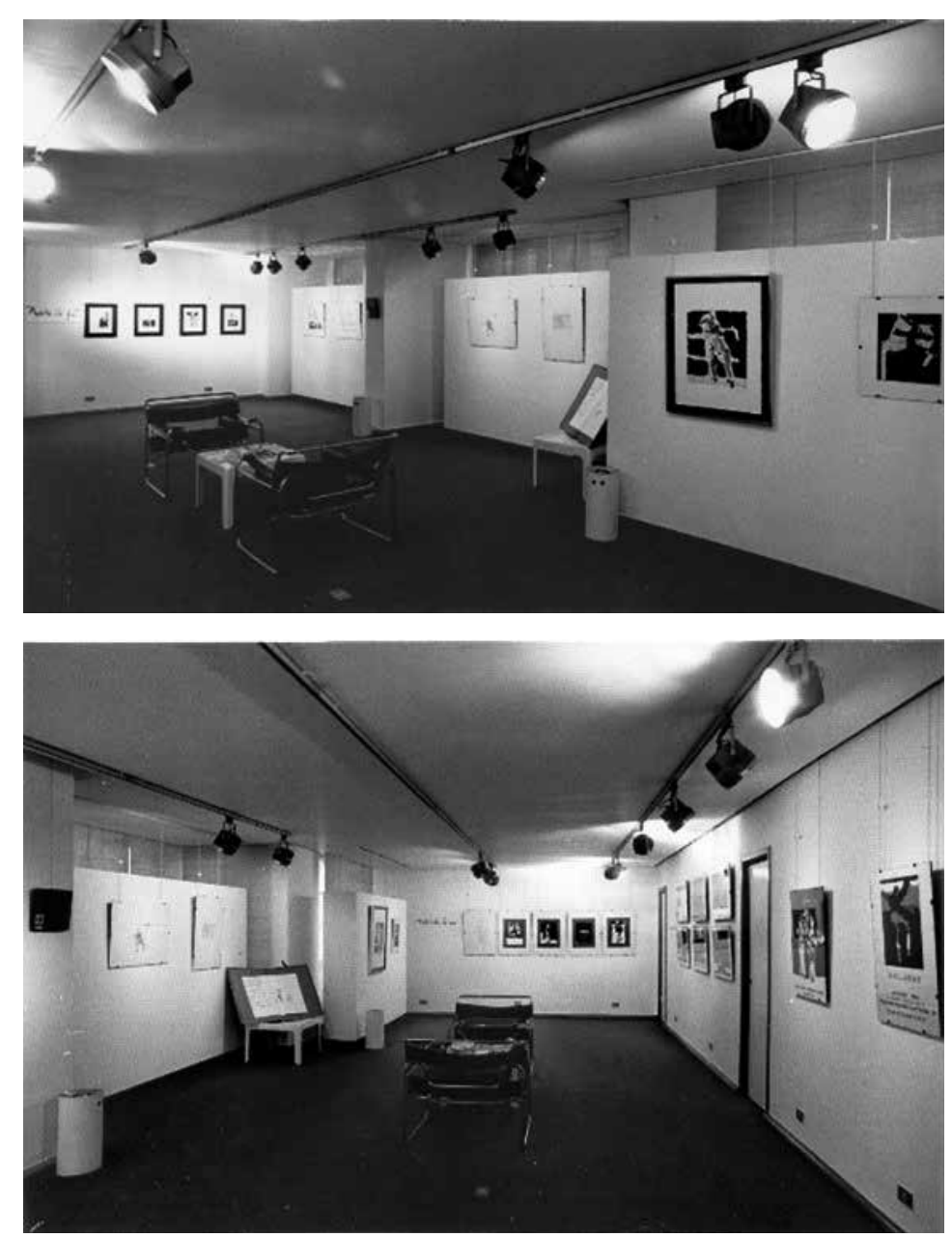

Figura 1.

Manolo Millares: Obra Gráfica, Galería Tassili, Oviedo, 1973. Archivo Tassili, Museo de Bellas Artes de Asturias, Oviedo.

cho comunicado con el vestíbulo, que continuaba a su vez con un prolongado pasillo. En paralelo a la calle principal de la ciudad se disponían obviamente, además del cuarto de dormir más relevante, el comedor y la sala, cuyos límites eran ya coincidentes con la esquina en chaflán tan característica que presenta este inmueble. Esta zona es la que se adaptaría tiempo más tarde para crear la galería Tassili, que únicamente utilizó una parte de la casa, de 229 metros cuadrados ${ }^{44}$.

La galería disponía de 46,72 metros cuadrados ${ }^{45}$, «toda vez que dicha vivienda continúa dedicada de modo principal a hogar familiar, conservando la vivienda las condiciones de habitabilidad reglamentarias» ${ }^{46}$. Castañón empleó una superficie cercana a los $60 \mathrm{~m}^{2}$ para depósito de obra ${ }^{47}$. Al cerrar la galería, el local pasó a tener otro uso bien diferente ${ }^{48}$.

La subida a la galería se efectuaba a través de una cómoda escalera, si bien también había un antiguo ascensor ${ }^{49}$ conducente a una suerte de recibidor exterior de la sala ${ }^{50}$. La vivienda disponía de dos entradas, principal y secundaria ${ }^{51}$.
Por tanto, se partía de una pieza rectangular no muy amplia y muy luminosa que conformaba un cuerpo sobresaliente y describía una forma regular ${ }^{52}$.

El cuidado proyecto ${ }^{53}$ fue ideado y materializado por José Antonio Menéndez Hevia ${ }^{54}$ (Oviedo, I938), que entonces regentaba la firma Díher, ejerciendo como un reputado interiorista perteneciente a la misma generación que el galerista. Castañón pidió a Menéndez Hevia que preservara una significativa parte del espacio disponible para vivienda, cuyo acceso estaba diferenciado de la sala de exposiciones y del almacén de obra.

El espacio (figura I) concebido por Hevia y Castañón era ante todo un local adecuado para cumplir con su función expositiva. Estaba definido por sus paramentos blancos y suponía un paso decisivo en la modernización del circuito tras los casos de las galerías Cristamol (1958) y Benedet (1964), anticipadas por el suntuoso local de la Obra Social y Cultural (1956).

Por otra parte, se empleó un sistema de cadenas para que los cuadros fuesen colgados con el fin de no dañar las delicadas paredes del edificio, dada la imposibilidad de clavar nada directamente en ellas. No había carriles adecuados en el mercado, así que se instalaron rieles convencionales de armario $^{55}$. Las cadenas se colocaron bajo una moldura de escayola, lo que resultaba muy cómodo y original. Igualmente, la firma Díher diseñó un zócalo redondeado para la sala de exposiciones ${ }^{56}$. Esto contrastaba con la solución que dio Carmen Benedet seis años antes a su complejo local, en que, asesorada por el arquitecto Joaquín Vaquero y una vez rebajado el techo dos metros con escayola, optó por colocar rieles de los que pendían bastones de diferentes tamaños para colgar la obra en suspensión.

El tratamiento lumínico fue muy novedoso. En principio, había excesiva luz natural debido a las numerosas ventanas existentes en la sala, lo que implicaba que no hubiera lienzos de pared para exposición suficientes. Para controlar la entrada de luz, el interiorista confeccionó unos volúmenes blancos que situó estratégicamente entre los pilares y a una altura de metro y medio, sin alcanzar el techo de la estancia y que además prolongaban el color neutro de los paramentos, logrando así aumentar los metros lineales disponibles. La parte superior de estos permitía la entrada de luz natural, si bien esta era regulada mediante la colocación de estores de bambú también importados que ayudaban a tamizarla ${ }^{57}$.

Para iluminar las obras de arte se instalaron rieles, a fin de insertar focos orientables y deslizables $^{58}$. Se pusieron también inéditas lámparas graduables del sistema Erco, de fabricación alemana, que permitían controlar la dispersión de luz ${ }^{59}$. Mientras, Benedet ya había reemplazado los 
focos colocados al principio por tubos de luz 57 de la firma Philips, que proporcionaban una luz muy similar a la natural.

Con el fin de obtener un aspecto uniforme, el tono elegido para la pintura del techo era similar al de la pared, pero dos tonos más oscuro. El solado era de madera de castaño y fue cubierto con una moqueta importada, danesa, de placas y tejida con lana de camello, que le confería un aspecto de tonalidades marrones. Ese color tabaco del pavimento contrastaba con los emblanquecidos muros de la sala, lo que aumentaba la sensación de profundidad del local, además de conferir gran calidez a la estancia. La idea que primaba en este proyecto era no distraer al espectador de la galería ${ }^{60}$, sin perder de vista la búsqueda del confort absoluto (luz, temperatura, humedad relativa, efectos hápticos, sonido ambiente).

Para el desarrollo de la actividad expositiva y cultural del establecimiento, Menéndez Hevia eligió un escueto mobiliario ${ }^{61}$ (figura 2) protagonizado por sillas tubulares $\mathrm{B} / 3$ Wassily, además de un par de mesas, un sofá y papeleras ${ }^{62}$. Suponía la idea de conjunto un avance considerable desde la propuesta institucional y anclada en la estética autárquica que concibió el Estudio Galán para la sala de la OSYC, abierta al público en I956. Dos años más tarde, el surtido mobiliario de la Sala Cristamol era mucho más moderno y cómodo, pero carente de la sofisticación introducida por Tassili. Antes, resulta llamativo el caso de la galería Benedet (1964), donde la práctica ausencia de muebles en el espacio expositivo dificultaba la reunión de los artistas y las tertulias, que sí tuvieron lugar en el sofá que circunvalaba el pilar del lujoso espacio de la galería Nogal (1969), con un acceso mucho más restringido y un estilo claramente retardatario.

Tassili por vez primera se reafirmaba como un lugar claro de encuentro en el modesto circuito local, y ello se reflejaba en la importancia concedida a la cuidada selección del mobiliario, parte de un proyecto de interiorismo y plenamente acorde con el discurso de la galería y de su promotor.

La galería, situada en un primer piso, precisó de una señalética adecuada, que se plasmó en la instalación de un rótulo de plástico (con luz) y dispuesto en bandera adherido a la fachada y una placa localizada junto a la puerta de ingreso al edificio.

Tampoco había un escaparate que hiciera de reclamo, algo que fue común a casi todas las salas pioneras ovetenses (Cristamol y Benedet). De este modo, se encargó una sencilla caja de madera, cerrada con llave y dotada de luz eléctrica, que permitía la exhibición de carteles diseñados por los artistas y que estaba colocada a la izquierda del portal. Cada artista confeccionaba

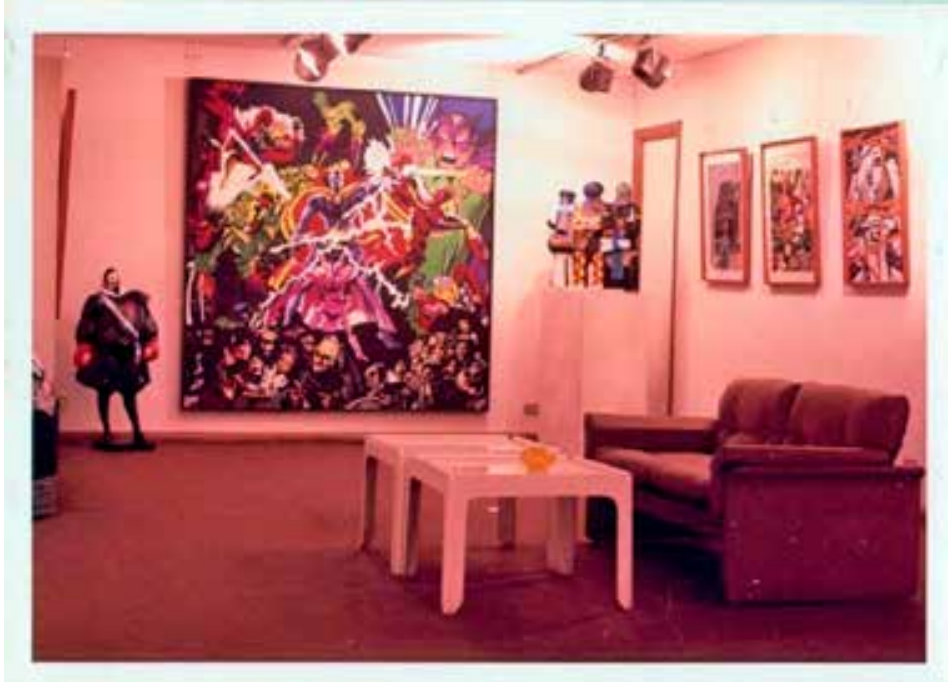

Figura 2.

Equipo Crónica, Galería Tassili, 1972. Archivo Tassili, Museo de Bellas Artes de Asturias, Oviedo.

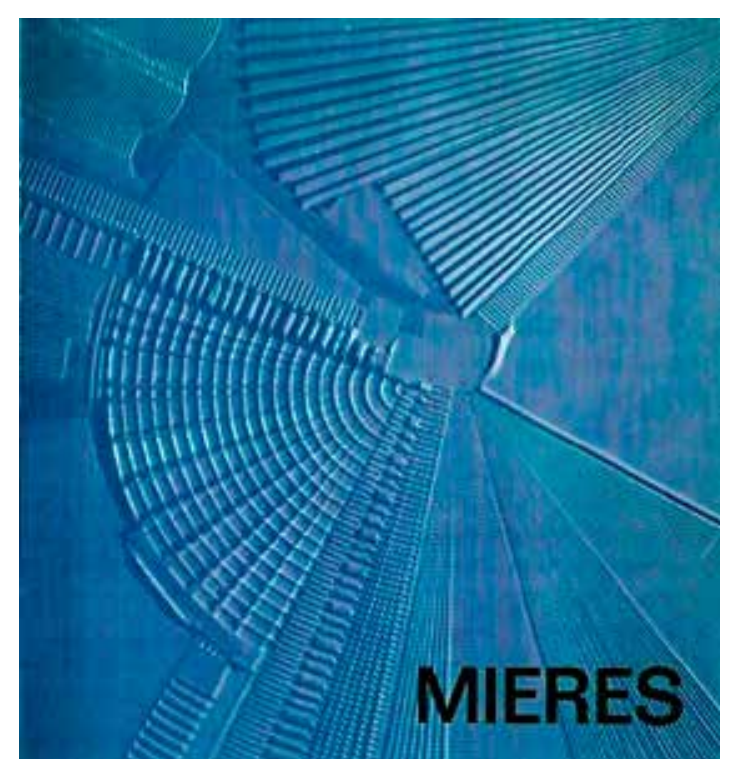

Figura 3.

Mieres: Óleos y tintas, Galería Tassili, Oviedo, 1977. Archivo Tassili, Museo de Bellas Artes de Asturias, Oviedo.

el catálogo y el anuncio a su gusto y teniendo en cuenta las medidas de la vitrina, que presentaba un formato vertical y no tenía paspartú, era todo luz. Los carteles medían $38 \times 25 \mathrm{~cm}$ aproximadamente, y la caja que los contenía, $50 \times 30 \mathrm{~cm}^{63}$.

En definitiva, se trataba de un espacio que permitía una mejor presentación de las exposiciones y que se amoldaba mejor que las salas ya existentes al arte que se estaba produciendo; ello a pesar de las evidentes limitaciones de un local que no dejaba de ser una parte de una vivienda. No obstante, la contratación de un profesional del diseño de interiores bien informado acabó por solventar los numerosos problemas iniciales y posibilitó la exhibición de pintura, escultura, 


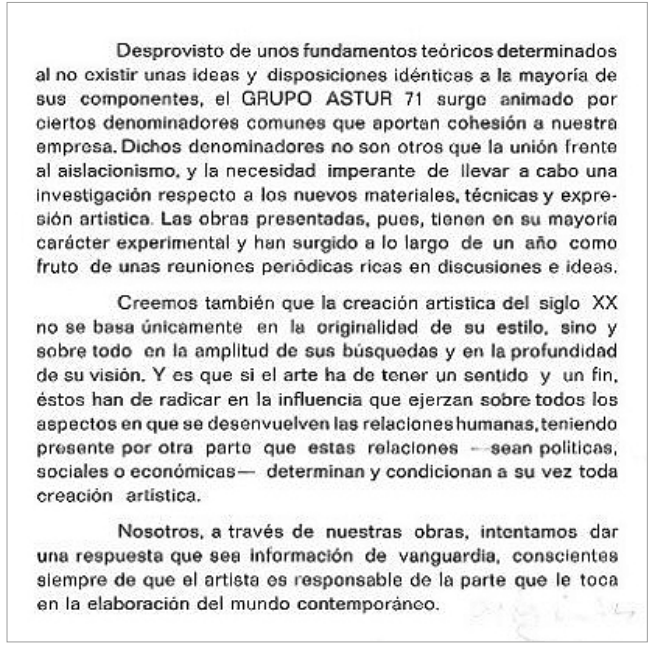

Figura 4

Astur 71, Galería Tassili, Oviedo, 1971. Texto del galerista. Archivo Tassili, Museo de Bellas Artes de Asturias, Oviedo.

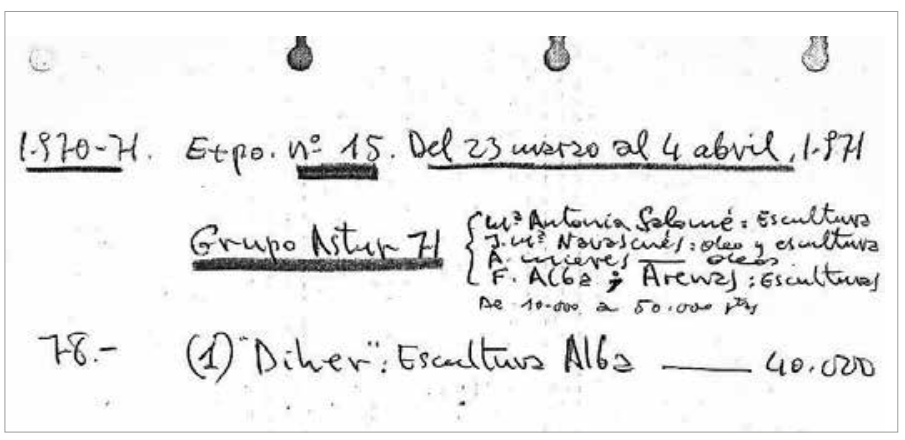

Figura 5.

Movimientos de venta. Astur 71, Galería Tassili, Oviedo, 1971. Archivo Tassili, Oviedo.

obra gráfica y hasta instalación en algunos casos. Además, el galerista se dotó de un buen número de pedestales y plataformas que permitían instalar todo tipo de piezas tridimensionales.

\section{El Manifiesto de la galería Tassili: ideario, líneas programáticas $\mathrm{y}$ expositores}

La extensa nómina de expositores de la galería indica una clara apuesta por el arte nuevo, sin concesiones. Su promotor no solo practicó esta arriesgada creencia, sino que también teorizó y divulgó los objetivos de su sala de arte en forma de manifiesto publicado en las páginas de Asturias Semanal ${ }^{64}$ y de la prensa local ${ }^{65}$. Entre estos propósitos estaban:

I. La promoción de los jóvenes creadores actuales noveles y especialmente de los que practiquen las nuevas tendencias.

2. La difusión del arte y la supresión de las barreras entre los nuevos lenguajes y el público.

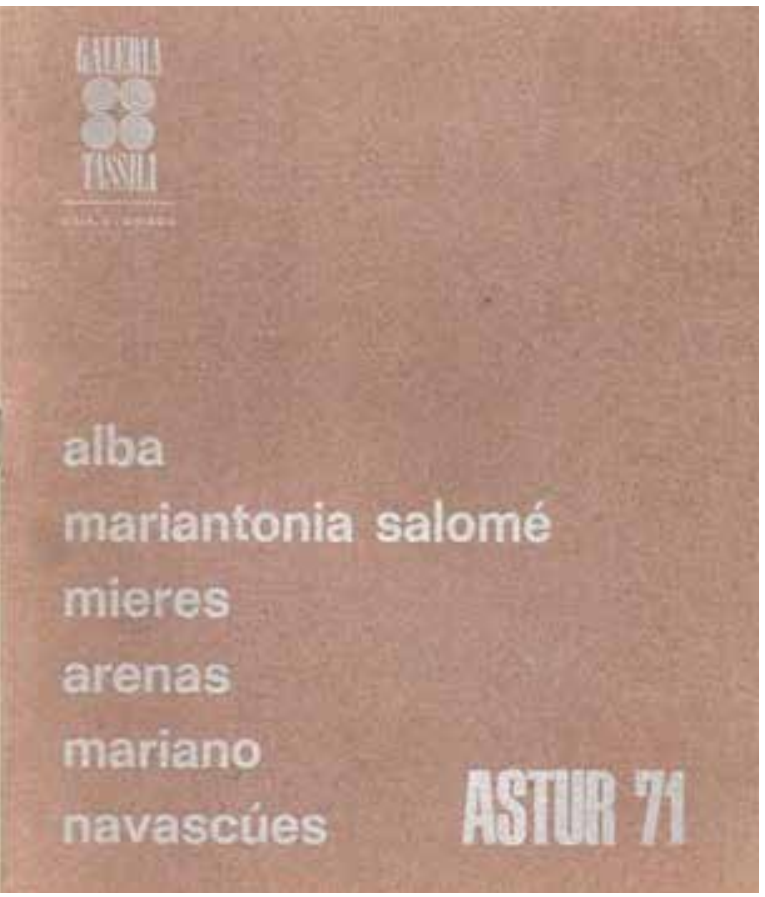

3. La generalización del coleccionismo de obra gráfica y múltiples entre los sectores sociales menos aficionados mediante la popularización de los precios y evitando que estos fueran abusivos.

4. La colaboración para que un público amplio adquiriese el hábito de visitar las exposiciones de la galería.

La inauguración estuvo protagonizada por Amparo Cores ${ }^{66}$ (Oviedo, I929 - Madrid, 20I 5), que seleccionó un conjunto de óleos ejecutados sobre madera y lienzo cuya temática eran el paisaje y el retrato ${ }^{67}$.

El número de $\operatorname{artistas}^{68}$ presentados en la galería Tassili fue muy destacado y se caracterizó por su compromiso firme con su tiempo, además de por su manifiesta calidad. Hubo I 43 exposiciones, entre individuales y colectivas ${ }^{69}$. En Tassili se expuso fundamentalmente pintura, escultura y grabado, y en alguna ocasión, tapices y cerámica ${ }^{70}$. La idea del galerista era que el 50\% de los artistas fueran asturianos y la otra mitad, foráneos, pero existía la tradicional problemática derivada de que los asturianos querían dominar el circuito local ${ }^{71}$. No obstante, si bien la galería ovetense presentó el trabajo, incluso de forma reiterativa, de algunos de los creadores que protagonizaban el panorama asturiano, esta cuidó que la representación de artistas nacionales (y en contadas ocasiones extranjeros) fuese significativa y muy diferente de la llegada en la posguerra a otras salas como Casa Basurto. Tassili consolidó la tendencia ya marcada desde años antes por Altamira, Cristamol y Benedet. 

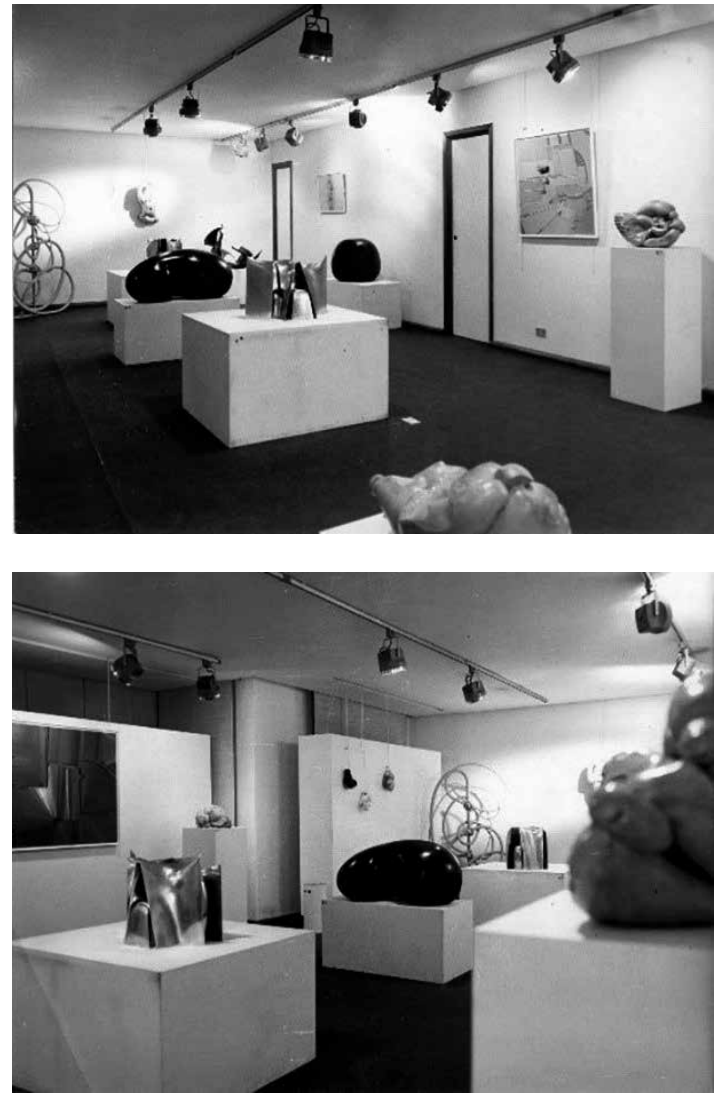

\section{Las exposiciones de Tassili}

Tras el estreno del local con Amparo Cores ${ }^{72}$, de la que se vendieron cinco obras, se exhibió en ese mismo mes de abril el trabajo de los artistas argentinos Esther y Guillermo Montenegro ${ }^{73}$. A continuación, Jesús González de la Torre ${ }^{74}$ mostró su visión del paisaje castellano, y José Luis Fajardo ${ }^{75}$, sus característicos aluminios.

En su primer cierre de temporada la galería organizó una muestra colectiva en que se reunieron obras de Castillo, Dalí (litografías), Mieres, Navascués, Eduardo Sanz (múltiples) y Úrculo (serigrafías) ${ }^{76}$, además de las de aquellos autores que expusieron desde abril hasta junio.

Una vez transcurrida la interrupción estival, las ventas de la galería comenzaron a crecer considerablemente. Los expositores de estos meses finales de 1970 fueron Guillermo Menéndez del Llano $^{77}$, Alejandro Mieres ${ }^{78}$ (figura 3), Manuel Jular $^{79}$, Armando Suárez ${ }^{80}$, Carmen Moya y Guillermo González ${ }^{81}$, que cerró el año con una selección de sus dibujos a lápiz.

En r 97 r la galería de la familia Castañón se consolidó en el circuito local. Así, Juan Gomi$1 a^{82}$ exhibió su pintura plástica sobre papel. Seguidamente ocuparon la sala diseñada por Menéndez Hevia el filipino Francisco Castillo ${ }^{83}$, la salmantina Isabel Villar ${ }^{84}$ y el artista local Car-

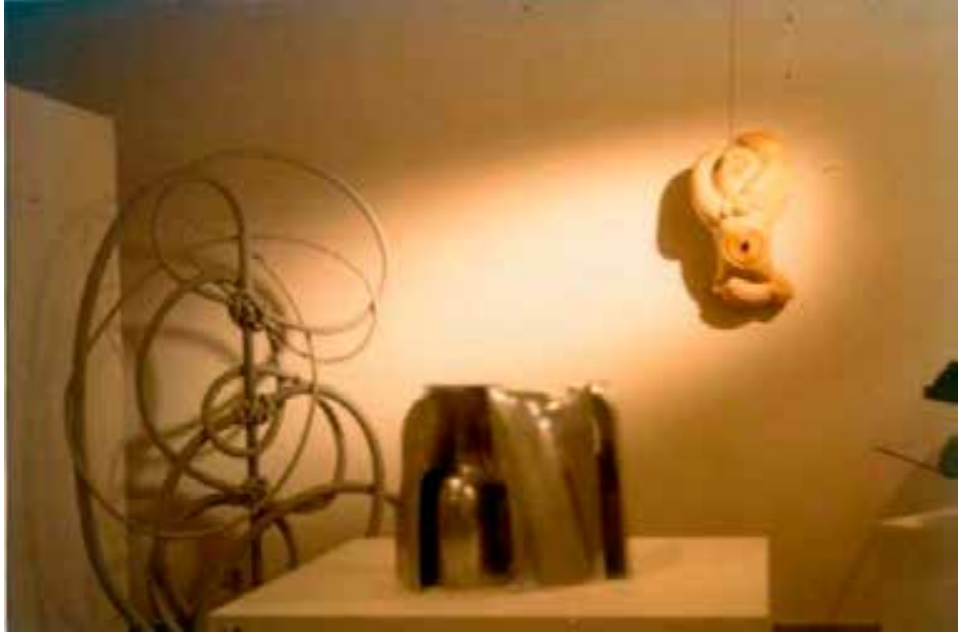

Figura 6.

Astur 71, Galería Tassili, Oviedo, 1971. Archivo Tassili, Museo de Bellas Artes de Asturias, Oviedo.

los Casariego ${ }^{85}$, además del grabador iraquí Faik Husen $^{86}$. Tras la colectiva anterior al verano, fue el turno de Humberto ${ }^{87}$, Bartolomé é8, Julián Casado $^{89}$, Jaime Herrero ${ }^{90}$ y Manolo Calvo ${ }^{91}$. En el mes de diciembre tuvieron lugar dos importantes muestras dedicadas a Eduardo Úrculo, uno de los creadores asturianos de mayor proyección, y a José Ortega. Úrculo exhibió trabajos ejecutados en pintura plástica sobre lienzo y también serigrafías entre el 2 y el i 8 de diciembre de 1971 en una exposición que fue un éxito de ventas ${ }^{92}$. José Ortega ${ }^{93}$, residente en París, reunió su serie «Durero» de grabados, cuya presentación constituyó un hito para la galería y la crítica la calificó de "extraordinaria»"

Por último, en ese mismo año, la sala presentó el trabajo conjunto del Grupo Astur $7 \mathrm{I}^{95}$ (figuras 4 a 6), influyente colectivo que llegó a congregarse en la galería también con el fin de debatir su moderno ideario artístico. La muestra, pese a su escasa rentabilidad económica, fue unánimemente aplaudida desde todas las cabeceras de la prensa local ${ }^{96}$.

El creador filipino Aro Soriano ${ }^{97}$ expuso en febrero de 1972, seguido por Carlos Casarie$\mathrm{go}^{98}$, ovetense y perteneciente a una saga muy arraigada en la ciudad, que cosechó un importante éxito al mostrar sus dibujos. No obstante, ese año lo más interesante fueron las propuestas de Ángel Orcajo ${ }^{99}$, Brosio $^{100}$ (figura 7), Agustín Ibarrola y Equipo Crónica (figura 8). Respecto a este importante grupo español contrario al informalismo imperante desde la década anterior y defendido por la galerista ovetense Carmen Benedet, se presentaron acrílicos sobre tela, serigrafías y múltiples valorados entre 5.000 y 75.000 pesetas. Fue una de las exposiciones más importantes celebradas en la galería Tassili ${ }^{101}$. 

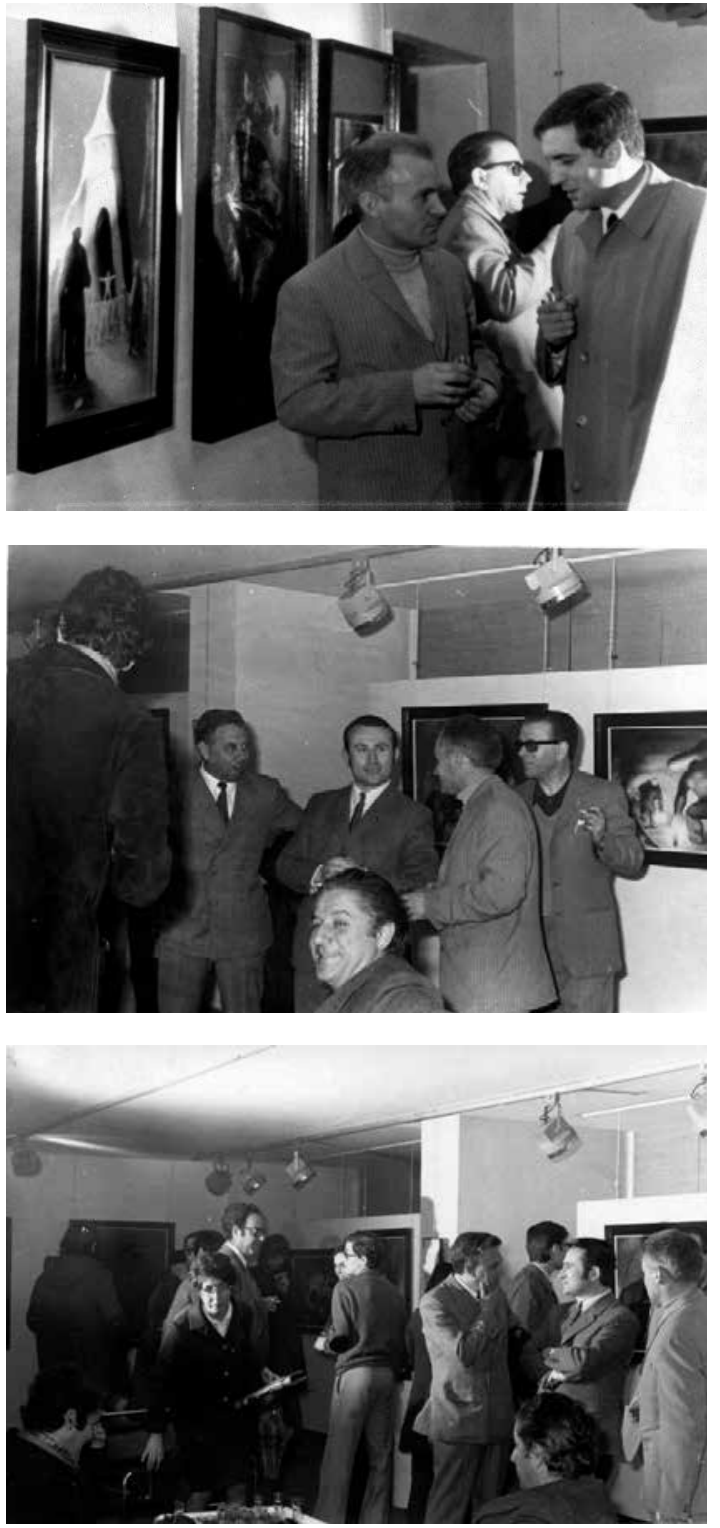

Figura 7.

Inauguración de la exposición Brosio, Galería Tassili, Oviedo, 1972. Archivo Tassili, Museo de Bellas Artes de Asturias, Oviedo.

Algunos artistas impensables en una galería de vanguardia se presentaban en todas las salas: Murillo, Marqués Uranga y la propia Tassili. Es el caso de Linares ${ }^{102}$, que mostró su trabajo en febrero de 1972 y en marzo de 1974.

Ibarrola ${ }^{103}$ (figura 9) expuso nuevamente en Oviedo su trabajo en mayo de 1972, tras haberlo hecho en la Sala Cristamol.

El año 1972 culminó con la individual de Elías Benavides ${ }^{104}$, que enseñó una selección de veinticinco gouaches en una muestra caracterizada por su particular sentido del grafismo y el predominio de la geometría. La colección de pinturas que presentó, esta vez empleaba «un estilo constructivo en cuanto a la composición geométrica de todos los temas y con una clara intención crítica». En aquel momento, el estu-

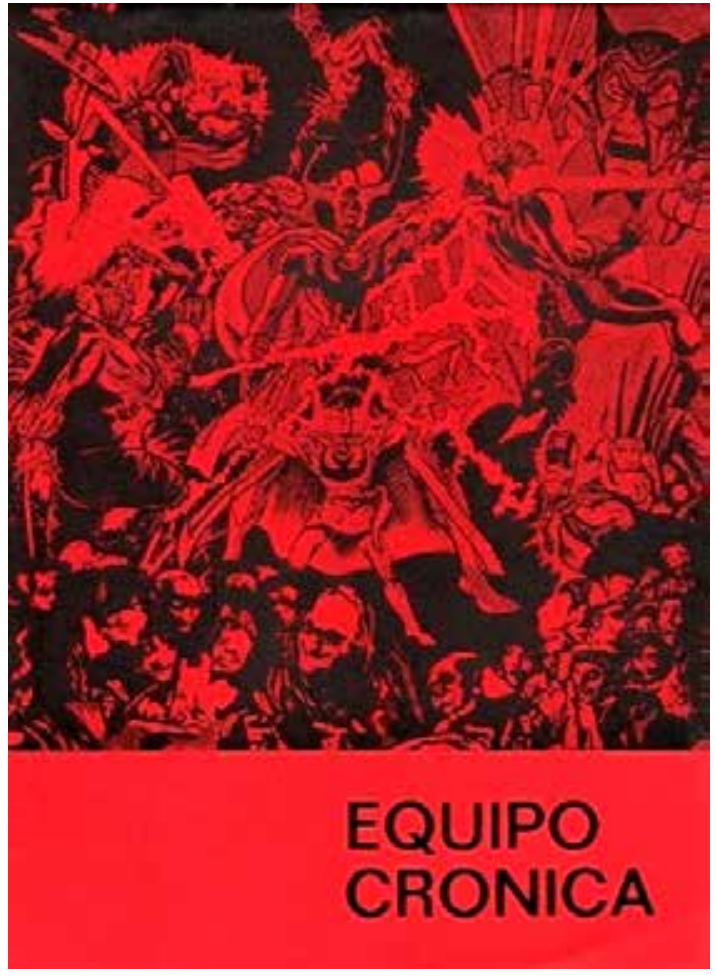

Figura 8.

Equipo Crónica, Galería Tassili, Oviedo, 1972. Archivo Tassili, Museo de Bellas Artes de Asturias, Oviedo.

dio de Elías y Santamarina «constituyen la más moderna e importante representación del arte gráfico asturiano» ${ }^{105}$. Por último, Ángel Guache ${ }^{106}$ expuso sus creaciones sobre cartulina.

El año I 973 se inició con una muestra conjunta de tres pintores asturianos ${ }^{107}$ : Urbano Cortina, Aurelio Suárez y Eduardo Úrculo. Esta fórmula volvió a repetirse en junio del mismo año, cuando se preparó otra exposición de conjunto en que se amplió la nómina de artistas locales ${ }^{108}$, que también protagonizaron de forma individual algunas de las exposiciones, como Ramón Rodríguez ${ }^{109}$, Armando Pedrosa ${ }^{110}$, Reyes Díaz ${ }^{111}$ y José Santamarina ${ }^{112}$. Entre las colectivas de este año sobresalió la programada bajo el título de «Serigrafías de artistas gallegos» ${ }^{113}$, gracias a la colaboración de la empresa SEGA, Serigrafías de Arte (Vigo) ${ }^{114}$, una de las exposiciones más rentables, al menos en cuanto a número de obras vendidas.

También en 1973 otra de las muestras destacadas de la galería estuvo protagonizada por Manolo Millares ${ }^{115}$ (figura Io) y se celebró un año después de su fallecimiento. Asimismo, el tinerfeño José Luis Fajardo ${ }^{116}$ expuso aluminios y grabados, y el ovetense residente en Madrid José Luis Fernández $z^{117}$ instaló sus esculturas. En diciembre, Marixa ${ }^{118}$, la pintora local exiliada en Francia, vendió sus óleos y sus tintas acuarelas.

En 1974 la galería dedicó curiosamente una muestra monográfica al pintor de historia y gé- 
nero Emilio Sala y Francés ${ }^{119}$ (Alcoy, I $850-$ Madrid, I9I0).

Otros artistas foráneos, como Luis Sáez ${ }^{120}$, Iturmendi ${ }^{121}$ y Leopoldo Novoa ${ }^{122}$, presentaron sus creaciones de forma individual. Igualmente, se pudo observar la evolución de los autores locales Mieres ${ }^{123}$, Bartolomé ${ }^{124}$ y Rafael Rubio ${ }^{125}$.

Es reseñable la apuesta por pintores, grabadores y escultores de la misma generación del galerista y también por presentar todo tipo de técnicas y formatos. Ponía a la misma altura el dibujo, la serigrafía o el collage y la acuarela.

$\mathrm{El}$ artista con mayores posibilidades de proyección internacional habido en el circuito asturiano contemporáneo, José María Navascués ${ }^{126}$ (figura I I), mostró sus esculturas entre el 3 y el I7 de mayo de 1974, además de sus dibujos. Las primeras tenían precios oscilantes entre $25.000 \mathrm{y}$ 200.000 pesetas, mientras que los segundos costaban entre I 8.000 y 22.000 pesetas. El año culminó con un nuevo éxito mercantil con las estampas de José Ortega $^{127}$.

Eduardo Gruber ${ }^{128}$, Francisco Castillo ${ }^{129}$ y Salvador Montesa ${ }^{130}$ presentaron sus últimas creaciones en el primer trimestre de 1975 .

La muestra número 76 de Tassili estuvo protagonizada de nuevo por Eduardo Úrculo ${ }^{131}$, que enseñó al público ovetense una selección de sus guaches, acrílicos y serigrafías.

Ese mismo año otros artistas asturianos protagonizaron exposiciones monográficas en la sala, como Rubén Darío Velázquez ${ }^{132}$, Miguel Ángel Lombardía ${ }^{133}$ y Bernardo Sanjurjo ${ }^{134}$, además de Chus Pérez de Castro ${ }^{135}$, Luis Cecchini ${ }^{136}$ y Vicente Iglesias ${ }^{137}$. Igualmente, expuso su trabajo el jienense Diego Moya ${ }^{138}$.

Por otra parte, en junio de 1975 , el H. A. Colectivo, formado por M. J. Antón, Juan Tomás Domínguez, Amelia Jiménez, Virginia Laceras, Rafael Núñez, Pilar Ortega y Pablo Sycet, expuso en Tassili, y la Hermandad Pictórica Aragonesa ocupó la sala de exposiciones entre el 8 y el 22 de octubre de 1975 .

En la línea marcada por el galerista respecto a Diego Moya el año anterior, el arquitecto Manuel Ayllón ${ }^{139}$ presentó sus esculturas en febrero de 1976. También volvieron a la galería Ramón Rodríguez $^{140}$, Elías ${ }^{141}$, Humberto ${ }^{142}$ y José Luis Fernánde ${ }^{143}$, entre otros. De los nuevos expositores sobresalieron las propuestas de Melquíades Álvarez $^{144}$ y Pelayo Ortega, José Paredes ${ }^{145}$ y Legaz$\mathrm{pi}^{146}$. Isabel Álvarez ${ }^{147}$ colgó sus óleos sobre papel y Javier Méndez ${ }^{148}$ enseñó sus guaches, temples y dibujos. Otra vez hubo hueco para artistas más conservadores, como el profesor Higinio del Va$1 \mathrm{e}^{149}$, que presentaba su primera individual.

La exhibición más recordada de aquel año corrió a cargo del pintor Carlos Sierra ${ }^{150}$, debido al montaje de la misma en forma de ocupación ins-

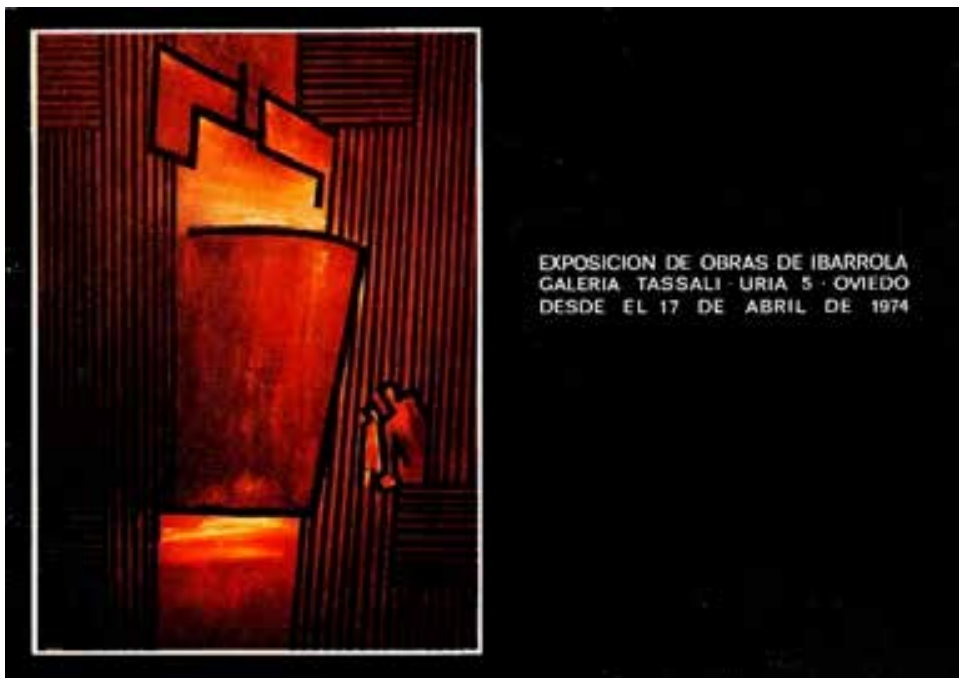

Figura 9.

Exposición de Obras de Ibarrola, Galería Tassili, Oviedo, 1974. Archivo Tassili, Museo de Bellas Artes de Asturias, Oviedo.

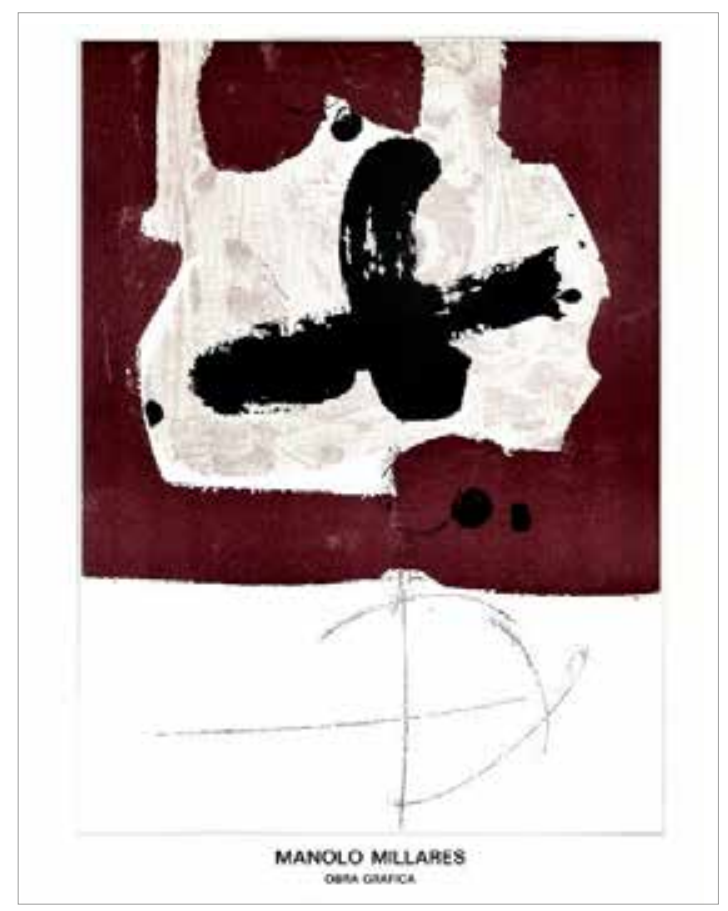

Figura 10.

Manolo Millares: Obra Gráfica, Galería Tassili, Oviedo, 1973. Archivo Tassili, Museo de Bellas Artes de Asturias, Oviedo.

talación. Asimismo, la primera exposición tras la interrupción del verano se orientó claramente a potenciar las ventas, ya que se trataba de nuevo de una muestra conjunta de Aurelio Suárez, Orlando Pelayo y Eduardo Úrculo ${ }^{151}$.

Una selección de los múltiples de Josep Guinovart ${ }^{152}$ abrió la actividad de la galería durante el año 1977 , en que retornaron con sus nuevas creaciones Guache ${ }^{153}$, Lombardía ${ }^{154}$, Mieres ${ }^{155}$, Sanjurjo ${ }^{156}$ y Santamarina ${ }^{157}$. Comparecieron con sus propuestas otros pintores locales, como Paz 


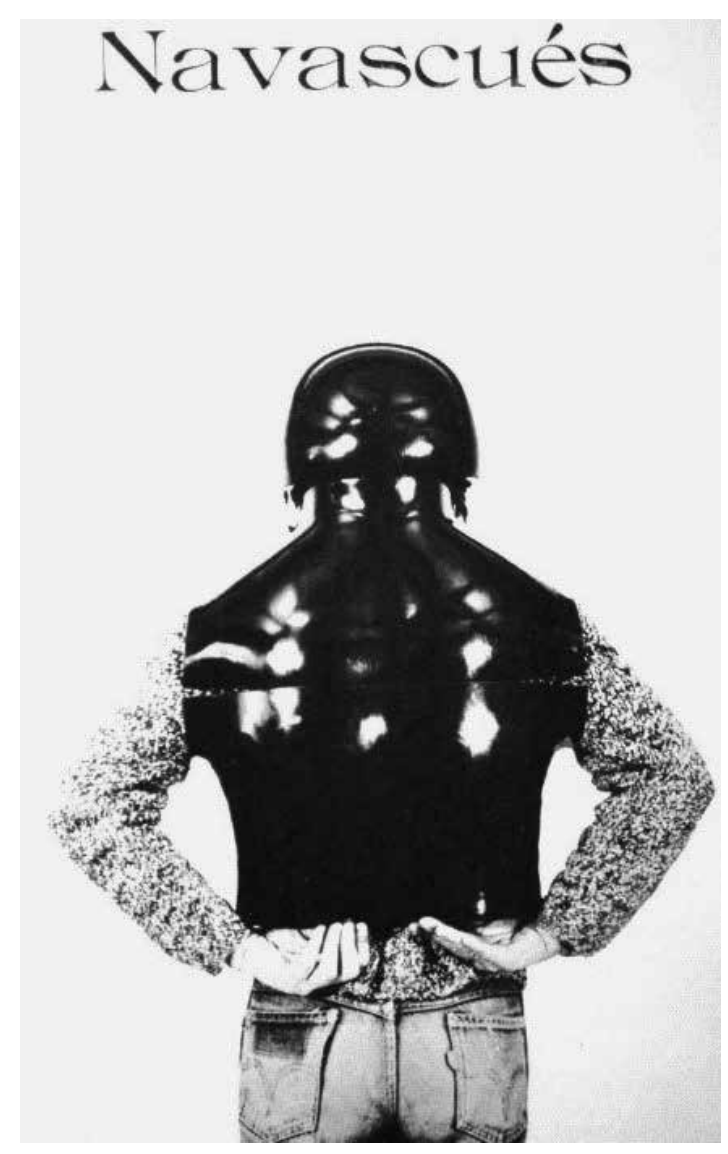

Figura 11.

Navascués: Esculturas, Galería Tassili, Oviedo, 1974. Archivo Tassili, Museo de Bellas Artes de Asturias, Oviedo.

Vial $^{158}$ y Kiker ${ }^{159}$. De los expositores foráneos destacó la exposición de cerámica de Rosa María Gimeno $^{160}$, la de pinturas y dibujos del ilicitano Albert Agulló ${ }^{161}$ y otra presentación del trabajo de Gruber ${ }^{162}$, pero esta vez de sus lápices.

La sala ovetense también hizo un hueco al arte de los españoles que trabajaron en París ${ }^{163}$. De este modo, en febrero de 1977 se montó una exposición con obra de algunos de sus principales representantes.

Una colectiva celebrada entre el 22 de marzo y el 2 de abril de 1977 mostró obra de Orlando Pelayo, Aurelio Suárez, Antonio Suárez y Marixa, y en Navidad ${ }^{164}$ se seleccionó parte del rico fondo de galería.

La penúltima temporada de actividad de Tassili confirmó su apuesta por algunos artistas, destacando la rica producción de Eduardo Úrculo ${ }^{165}$ y el regreso de Amparo Cores ${ }^{166}$, que había inaugurado la sala. A estos se unió la presentación de los pintores Consuelo Vallina ${ }^{167}$, Luis Garrido Acosta ${ }^{168}$, José Ramón Muñiz ${ }^{169}$ y sobre todo de los escultores Amador ${ }^{170}$, Basagoiti ${ }^{171}$ y Nava Iglesias ${ }^{172}$.

José María Navascués ${ }^{173}$ (figura I 2) expuso el año anterior a su muerte. Esta vez el público pudo contemplar algunos dibujos y maderas en relieve

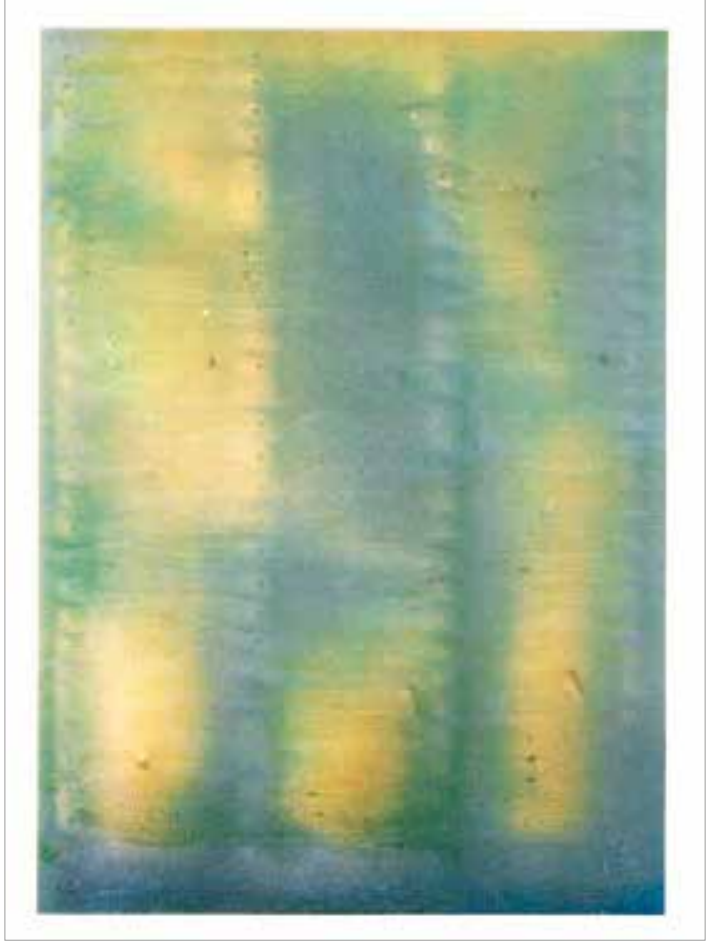

Figura 12.

Navascués, Galería Tassili, Oviedo, 1978. Archivo Tassili, Museo de Bellas Artes de Asturias, Oviedo.

pintadas, cuya valoración económica oscilaba entre las 35.000 y las 140.000 pesetas.

Los meses finales de este comercio artístico no destacaron por su programación, en la que estuvieron presentes Ramón Prendes ${ }^{174}$ y Pepa Osorio $^{175}$. No obstante, la exposición número I 43 con que se clausuraba el brillante ciclo de esta moderna sala de arte sí sobresalió por la propuesta estética elegida. Así, Fernando Alba ${ }^{176}$ (figura I3) expuso sus esculturas en madera y bronce. La impactante obra sobre troncos de madera ejecutada por Alba puso punto y final en junio de 1979 a una intensa trayectoria que llenó prácticamente toda la década de los años setenta. La galería cerró definitivamente en septiembre del mismo año ${ }^{177}$.

\section{La relación de Tassili con otras} galerías y con los artistas: actividad cultural bajo la censura

El responsable de Tassili mantuvo trato comercial con establecimientos localizados en las principales plazas de la geografía española. J. A. FernándezCastañón vendió obra de las empresas madrileñas Grupo Quince, Ele, Juana Mordó ${ }^{178}$, Sen, IolasVelasco, De Luis y Estiarte ${ }^{179}$, de la valenciana Punto $^{180}$ y de las barcelonesas Polígrafa ${ }^{181}$ y Maeght, entre otras. También colaboró con la Sala Provincia, de León, para que programara una muestra

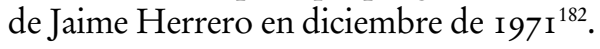


La galería ovetense extendió sus relaciones a varias publicaciones especializadas, entre las que estaba la revista calcográfica Graba 2.

Los cuadros expuestos eran enmarcados en Nogal, Cristamol y Shalom Art. También hubo trato profesional con Altamira, pero no con Benedet ${ }^{183}$.

Tassili se hizo eco del ambiente crítico, artístico y político ${ }^{184}$ que se vivía en algunos locales madrileños fundados en aquellos mismos años, entre los que sobresalió el papel aglutinador de Buades ${ }^{185}$, galería abierta en I 973 bajo la dirección artística de Juan Manuel Bonet.

Se programaron veladas de poesía y música a cargo de los cantautores activistas Paco Ibáñez (Valencia, 1934) y Xavier Ribalta (Tàrrega, Lleida, I943), esta última sin el preceptivo permiso oficial, lo que provocó una amonestación ${ }^{186}$ gubernamental. La autoridad provincial de Oviedo remitió un escrito al «propietario de la sala de exposiciones Tassili» por haber presentado el día 7 de abril de I972 «un recital a cargo del cantante catalán Xavier Ribalta», puesto que este

[...] no había sido autorizado por este Gobierno Civil de conformidad con lo dispuesto en la Orden del Ministerio de la Gobernación de 20 de Julio de 1939 y como quiera que entre las competencias atribuidas a mi Autoridad por el Decreto de io de Octubre de 1958 figura la de velar para que las actividades relacionadas con festivales, espectáculos públicos, culturales y similares se realicen conforme a las normas e instrucciones y similares ${ }^{187}$.

Igualmente, se acogió a artistas significados políticamente, como Ibarrola y Brosio.

Era cotidiana la obligación de dar cuenta de la actividad de la galería en el Departamento de Censura de la Delegación del Gobierno. Para obtener las autorizaciones que permitían realizar la actividad de la galería debían cumplimentarse unos formularios oficiales en que se consignasen los datos del artista con su currículum, el título de la muestra y las fechas en que esta se pretendía celebrar. $\mathrm{Al}$ día siguiente de entregar la instancia, si se daba el visto bueno, se recogía la credencial en la sede del organismo correspondiente ${ }^{188}$.

El grupo de creadores Astur 7I, como ya se ha señalado más arriba, fue objeto de una importante exposición en la primavera de i97i que sumó la colaboración del propio José Antonio Fernández-Castañón, que participaba en las reuniones $^{189}$, ocasionalmente celebradas en la galería, donde presentaron sus trabajos a modo de manifiesto ${ }^{190}$. Estos cenáculos de Astur 7I tenían lugar en la sobremesa (tras la comida), si bien la mayoría de los encuentros transcurrieron en el estudio de Alejandro Mieres ${ }^{191}$ y se materializaron a través
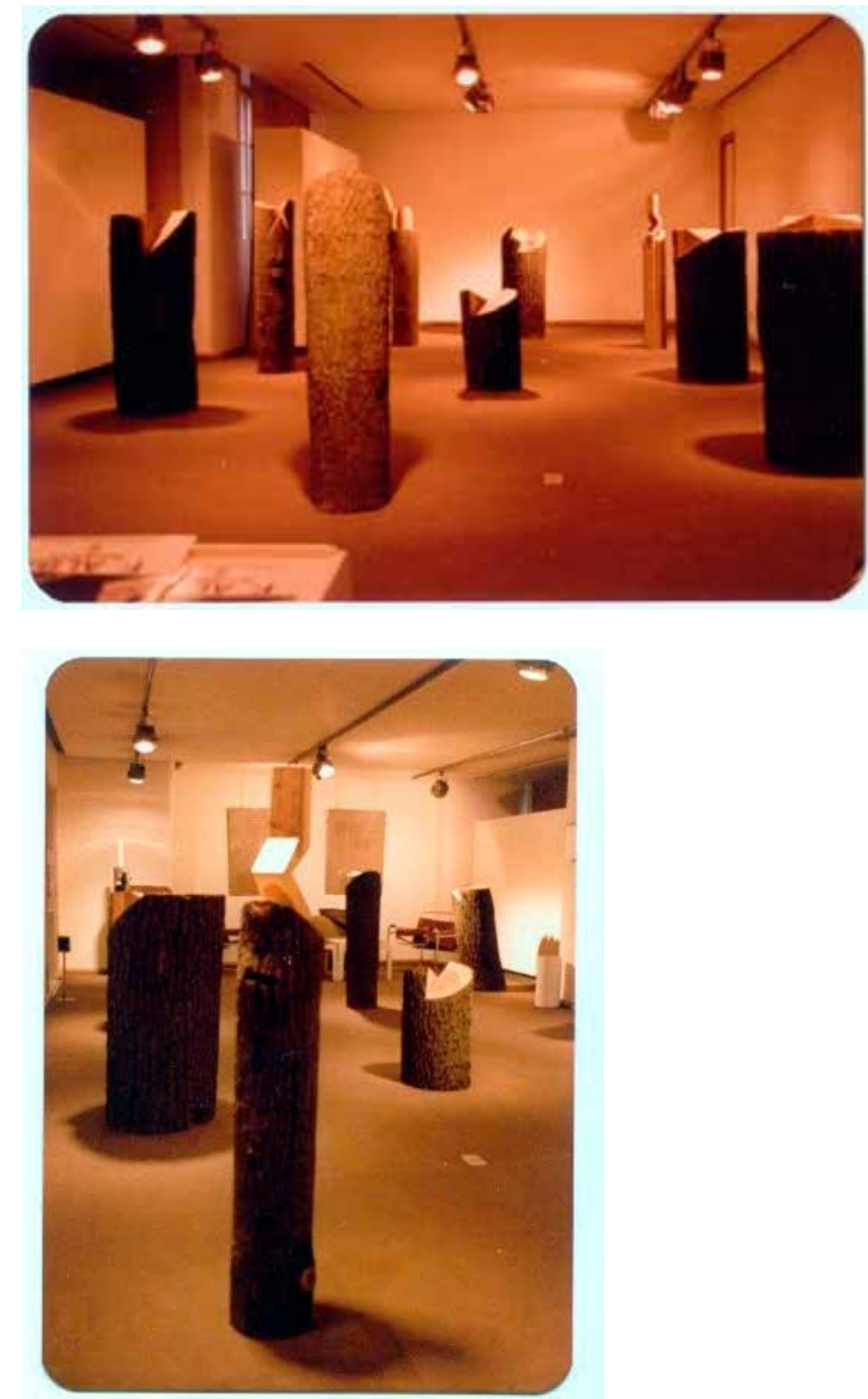

Figura 13.

Fernando Alba, Galería Tassili, Oviedo, 1979. Archivo Tassili, Museo de Bellas Artes de Asturias, Oviedo.

de la presentación pública del grupo en Tassili el 23 de marzo.

Esta experiencia fue extraordinariamente importante en la trayectoria de las salas de arte contemporáneo asturianas, pues era la primera vez en que una galería servía como aglutinante para un conjunto de artistas renovadores simplemente amalgamados por esta y por su intermediario. Castañón cumplió su papel de enlace y posibilitó que lo más nuevo y espontáneo entrase en su sala de exposiciones en un momento en que apenas había lugares para que este tipo de obras fueran mostradas tanto en el circuito público como en el privado, ambos aún muy conservadores. En el propio catálogo se incluía un texto de José Antonio Fernández Castañón en que este justificaba 


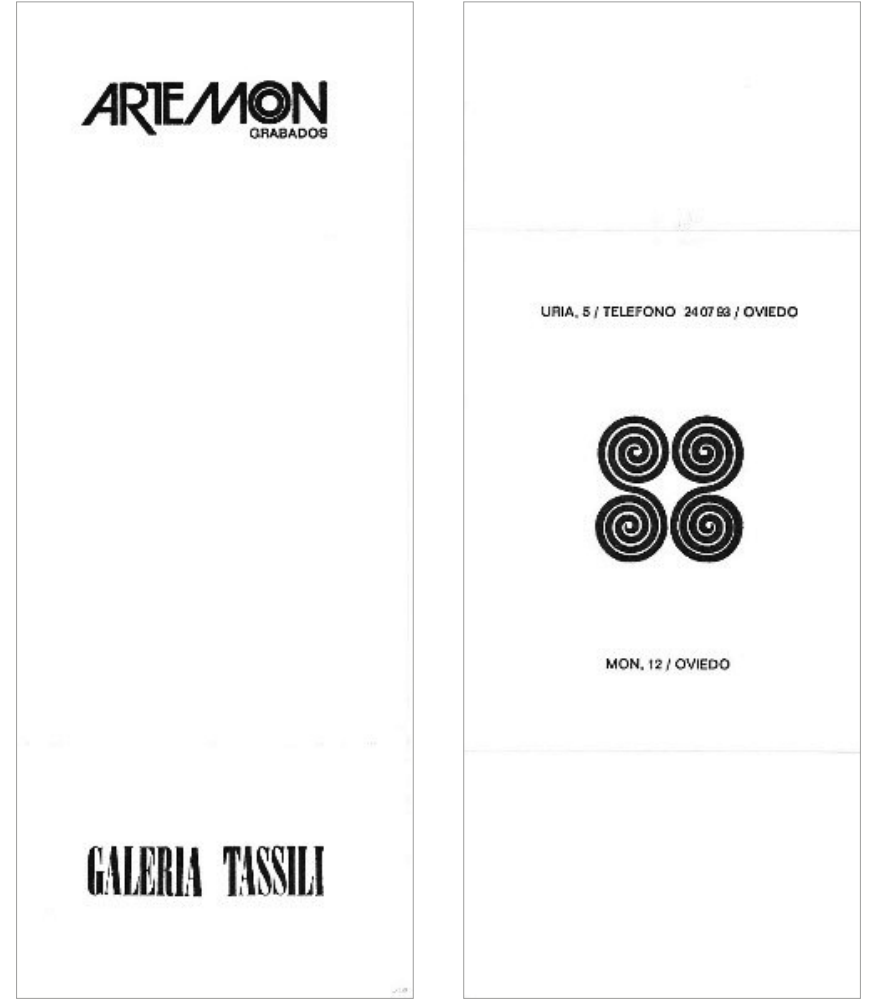

Figura 14.

Tarjeta Galería Tassili-ArteMon Grabados, Oviedo. Archivo Tassili, Oviedo.

«la unión frente al aislacionismo, y la necesidad imperante de llevar a cabo una investigación respecto a los nuevos materiales, técnicas y expresión artística». Por tanto, las obras expuestas tenían «en su mayoría carácter experimental y han surgido a lo largo de un año como fruto de unas reuniones periódicas ricas en discusiones e ideas» ${ }^{192}$. Las exposiciones de Astur $7 \mathrm{I}^{193}$ significaron ante todo una forma de tanteo con los materiales, eso unía a los artistas que componían el grupo, muy diferentes entre sí. De este modo, Salomé empleó tuberías de plástico; Ciagar, la gomaespuma; Arenas, los hierros; etc. Además, contaban con la figura de Navascués, que estaba muy informado del estado del arte internacional ${ }^{194}$.

Por otra parte, la Asociación de Artistas Asturianos se gestó en Tassili, donde tuvieron lugar sus primeras reuniones y de la que uno de sus habituales expositores locales, Miguel Ángel Lombardía, fue el primer director ${ }^{195}$.

\section{La imagen gráfica de Tassili y sus publicaciones: ferias y régimen fiscal}

El logotipo (figura I4) de la galería, de resonancias orientales, es una creación del estudio de Elías \& Santamarina ${ }^{196}$, radicado en Oviedo desde $1969^{197}$. Tassili destacó por sus cuidadas y modernas edi- ciones (catálogos de mano, carteles y tarjetas) también a cargo de la firma de diseño mencionada. Se trataba de la primera vez en la región en que la imagen gráfica de un establecimiento de este tipo se profesionalizaba. Los integrantes del estudio, Elías García Benavides (León, 1937) y José Santamarina (Oviedo, I94I), fueron asiduos expositores de la sala ovetense. Mucho tiempo antes ya tenía interés lo que planteaba, en ese mismo sentido, el asturiano Manolo Arce para la galería Sur de Santander ${ }^{198}$.

En la mayoría de los casos, los folletos fueron editados en la Imprenta Maguncia ${ }^{199}$. Y aunque se publicaron textos teóricos sobre Agustín Ibarro$\mathrm{la}^{200}$ y una obra literaria de Ángel Guache ${ }^{201}$ titulada Apariciones, en 1979, el galerista no llegó a editar obra gráfica ni libros de artista.

A pesar de que en la segunda mitad de la década comenzó a cobrar cierta importancia la concurrencia por parte de las galerías de arte contemporáneo a las ferias, principalmente de Barcelona (Artexpo) y París (Fiac), Fernández-Castañón no acudió a este tipo de eventos ni tampoco concedió premios $^{202}$.

Las inspecciones realizadas por los responsables de la Hacienda Pública se incrementaron en la década de los años setenta, y ello se tradujo en una mayor presión fiscal sobre la actividad de las galerías de arte. De este modo, el subdelegado de la Inspección de la Delegación de Hacienda de Oviedo dirigió una carta al responsable de la Galería Tassili el 29 de marzo de 1978 , mediante la que recordaba a este «la obligación de remitir a esta Delegación de Hacienda, los datos relativos a las exposiciones en ella efectuadas desde el ejercicio de i976». A esta misiva añade un documento a modo de formulario en que se debían apuntar «los datos a facilitar con respecto a cada una de las exposiciones en ella celebradas», que había que remitir a la Unidad de Información de la Inspección de Hacienda. De acuerdo con la Orden de 23 de junio de 1973, se requería a los artistas que consignaran: nombre y apellidos, DNI, domicilio, año, número de obras vendidas y el importe total percibido ${ }^{203}$.

Por tanto, en estos años se observa la aplicación de medidas no solo de control ideológico, sino también económico y recaudatorio, dado que en los años setenta la profesión de galerista ya tenía un buen número de altas en el registro correspondiente. También se pretendía llevar a cabo un mayor seguimiento de los ingresos reintegrados por los artistas.

\section{Ventas y funcionamiento del depósito de obra: clientela}

Las ventas de obra procedente del depósito ${ }^{204}$ eran la clave del mantenimiento del negocio. Sorpren- 
de el hecho de que el fondo de galería denominado depósito fuera conformado básicamente por obras del mismo carácter que lo expuesto en la sala temporal, esto es, de arte contemporáneo. En este había obra asturiana y también de artistas foráneos, muchas veces procedentes de particulares que vendían sus colecciones. Por lo demás, era habitual la cesión de obra gráfica por parte de otras galerías $^{205}$, aspecto este muy cuidado en la nueva sala ovetense, que buscaba fomentar la venta de obra múltiple en la región.

El enriquecimiento y la gestión del fondo de galería fueron muy cuidados por Fernández-Castañón, algo que ya había puesto en práctica seis años antes Carmen Benedet en su negocio.

Las más de ciento cuarenta exposiciones de Tassili sumaron una regular y buena acogida económica. Castañón consignó de una forma ordenada todas sus ventas, entre las que, junto a las pinturas, no escaseaba la obra gráfica ni la escultura, incluso la de carácter más experimental, casi siempre a precios asequibles. En el primer año de la firma, cumplido en marzo de I97 I, ya se habían hecho 77 ventas. Justo desde esa fecha el galerista empezaba a contar con un depósito bien organizado y a dar salida al fondo almacenado.

Algunas de las muestras más arriesgadas, como la del grupo Astur 71, bajaron el nivel de ventas ascendente de la sala. No obstante, fueron rentables a nivel económico las de Equipo Crónica (1972) y Manolo Millares (1973). En 1976, coincidiendo con la exposición de Eduardo Úrculo (número 76) la galería de Castañón había hecho 702 movimientos de venta, sumando las temporales y lo que salía del depósito, y aún quedaba casi la mitad de muestras que presentar antes del cierre del local.

Los almacenes de obra eran estrictamente controlados y se expedían unos cupones a los artistas que facilitaban sus creaciones, tanto para su ingreso en el depósito como para su exhibición temporal en la sala de exposiciones. Así, el escultor Fajardo recibió su documento acreditativo con el membrete de la galería en que se decía literalmente: «Para su exhibición y venta a mi nombre he depositado en la Galería Tassili de Oviedo la cantidad de 24 obras. En idénticas condiciones y por un plazo de... dejo en depósito cuatro obras. Oviedo, 3 de noviembre de 1973. Firmado José Luis Fajardo»206.

Igualmente, para el procedimiento de cesión del local con fines expositivos, Castañón entregaba otro tipo de recibí en que literalmente se anotaba lo que se apunta en este ejemplo:

He recibido de D. José M. Sainz Ruíz la cantidad de 4.000 ptas., en concepto de alquiler de uso de los locales de la Galería Tassili, de Oviedo, destinados a exhibición de obras de arte y venta de las mismas por cuenta del autor o arrendatario. Exhibición del 26-III al 6-IV de 1974. Oviedo, 26 de marzo de 1974. Fdo. El arrendatario (Sainz Ruiz) y el arrendador (Castañón) ${ }^{207}$.

Por tanto, el galerista expedía recibos tanto por los depósitos de obra como por el alquiler del uso del local a sus expositores ${ }^{208}$. El resultado era un estricto, racional y riguroso control del fondo disponible, así como del empleo del espacio expositivo por las dos partes que participaban en el acuerdo comercial.

Para obtener la licencia fiscal por el alta de la galería debían abonarse i. 500 pesetas (en 1978) en concepto de alquiler del local ${ }^{209}$.

La sala llegó a concentrar una nutrida cartera de clientes ${ }^{210}$, entre los que sobresalían muchos integrantes de la nueva burguesía ovetense de aquel tiempo, que, a diferencia de la de posguerra, más interesada en productos retardatarios, comenzaba a coleccionar arte contemporáneo de forma tímida, algo que se constata desde finales de los años cincuenta en Cristamol y, sobre todo, a partir de 1964 con la sala de Carmen Benedet. De este modo, Tassili consolidó esa tendencia y a los compradores señalados más arriba habría que añadir algunos arquitectos, profesores universitarios y miembros de conocidas familias locales, entre otros muchos. Asimismo, Andrés Tamés ${ }^{211}$ del Valle fue cliente asiduo de la galería, y su colección, actualmente propiedad del Ayuntamiento de Oviedo, refleja en buena medida parte de la trayectoria de la misma.

Igualmente, el Instituto Nacional de Enseñanza Media Bernaldo de Quirós, de Mieres ${ }^{212}$, que posee una importante colección de arte contemporáneo, incorporó algunas piezas procedentes de la galería en el período en que su directora, Carmen Díaz Castañón, fue asidua visitante. El propio galerista, que cobraba un $25 \%$ en concepto de comisión por las ventas efectuadas, se quedaba con una obra pequeña elegida por el artista ${ }^{213}$.

Del depósito de la galería salieron también obras de arte con destino a locales de hostelería $^{214}$ coetáneos de esta. La Universidad de Ovie$\mathrm{do}^{215}$ adquirió varios grabados para una de sus facultades.

La sala vendió obra de un artista retirado de la vida pública de indudable interés, Aurelio Suárez, cuyos precios oscilaban entre las 3.000 pesetas y las 28.000. Eduardo Úrculo fue uno de los pintores de los que vendió más piezas.

Respecto al público de la galería, estuvo compuesto principalmente por personas con profesiones liberales y estudiantes. La primera muestra congregó a I0.000 visitantes ${ }^{216}$.

Otro asunto del que se ocupó el galerista fue el de la difusión de su actividad en los medios de 
comunicación, aspecto clave para un negocio del tipo que se trata y que conocía bien, debido a que había ejercido como redactor de arte hasta poco tiempo antes de abrir la sala. En este período en que el dinamismo expositivo se acrecentaba en la región, la prensa escrita local comenzó a dedicar un espacio más adecuado en sus páginas semanales. Los responsables del diario La Nueva Espa$\tilde{n} a$ informaron a los interesados que, a partir de febrero de i974, las «inserciones» serían de pago e irían incorporadas en una gaceta de exposiciones. Desde la galería debían redactar una nota de prensa para el rotativo ovetense $\mathrm{e}^{217}$, algo que, pese al tiempo transcurrido, sigue siendo el procedimiento habitual y la base de las informaciones aparecidas en los medios locales.

Las exposiciones de Tassili fueron especialmente atendidas ${ }^{218}$ por la prensa, y Castañón conocía perfectamente el funcionamiento de los periódicos activos en la región y de sus redacciones. Además, el galerista tenía un conocimiento claro de la precaria oferta expositiva existente en Asturias y sabía que los creadores adscritos a las nuevas tendencias no estaban lo suficientemente atendidos. Tassili fue bien vista por los críticos locales más influyentes, como Jesús Villa Pastur, si bien su cierre prácticamente coincidiría con la organización de los estudios de Historia del Arte, que desde poco tiempo después contarían con una revista académica, Liño, donde ya se revisaría el circuito de una forma complementaria a la de los periodistas, aunque sin la presencia de Tassili.

\section{ArteMon Grabados (I 974)}

Tassili presentó y vendió obra gráfica, un objeto artístico que permitía incrementar notablemente las ventas. Esto animó a su propietario a abrir un local asociado a la galería principal que estuviese dedicado exclusivamente a la comercialización de estampas, aspecto este en que de nuevo fue precursor ${ }^{219}$ en la región. De este modo se daba salida al fondo de grabado de Tassili. Esta circunstancia se inscribe indudablemente en un contexto, a mediados de los años setenta, en que otra de las principales galeristas que operaban en Oviedo y principal competidora, Carmen Benedet, ya vendía importantes cantidades de obra gráfica.

La apertura del establecimiento en un bajo del número I 2 de la calle Mon, en pleno casco histórico de Oviedo, fue celebrada en el último tramo de $1974^{220}$, si bien la licencia municipal ${ }^{221}$ que permitía poner en funcionamiento este nue- vo comercio había sido expedida el 6 de julio del mismo año ${ }^{222}$.

No obstante, la duración de esta modesta tienda que derivaría finalmente en librería no llegó más allá de junio de $1978^{223}$, y su cierre anticipó el de Tassili.

El establecimiento presentaba un programa espacial muy limitado, que se componía de un vestíbulo y una sala para exhibiciones artísticas. En total, el local sumaba una superficie aproximada de 74 metros cuadrados ${ }^{224}$.

ArteMon programó pocas exposiciones ${ }^{225} \mathrm{y}$ se dedicó preferentemente a la venta de fondo de galería, para lo que fue empleado Javier Rodríguez Muñoz (nacido en i948).

La sala se inauguró con una muestra del grupo Arte en Asturias ${ }^{226}$ el I4 de noviembre de I974, en que se seleccionaron 35 estampas ${ }^{227}$. Este colectivo activo en 1974 y $1975^{228}$ se mostró contrario al comercio artístico tradicional, aún vigente en la región. Su papel lo continuó y desarrolló en mayor medida la Asociación Asturiana de Pintores y Escultores, también vinculada a Tassili y Tantra.

Entre 1977 y el cierre no hubo exposiciones individuales, sino que se renovaron sucesivamente los fondos de Tassili, que se convirtió en una librería de venta de grabados y libros ${ }^{229}$.

\section{Conclusiones}

Tassili ofreció una mayor profesionalización y un avance superior al emprendido por la Sala Cristamol, que había abierto el camino al arte contemporáneo en la ciudad y había servido para promocionar a creadores de interés como Úrculo e Ibarrola, cuyas evoluciones también se mostraron en la nueva galería de la calle Uría, donde los artistas locales encontraron un claro referente. Se puede establecer cierta continuidad entre ambas salas, siendo la de Castañón mucho más sólida y completa. Juntas llenan dos décadas plenas de acontecimientos artísticos fundamentales en Oviedo y se apartan del otro modelo vigente defendido por Carmen Benedet, firme en su apuesta por los informalistas españoles.

Así, más de cuatro décadas después de su cierre, la galería Tassili se presenta como un espacio expositivo con $\mathrm{voz}$ propia en el circuito español de los setenta, donde mantuvo una intensa y medida actividad durante casi diez años, por lo que se convirtió en un referente, pese a su limitada localización geográfica, para los expositores y el público. 
* Este trabajo se enmarca en una investigación más amplia comprendida en nuestra tesis doctoral, titulada Galerías de arte en Asturias: espacios y promotores (1918-2005), dirigida por Javier Barón Thaidigsmann y defendida en la Universidad de Oviedo el año 2015. Además, el año 2006 se presentó una comunicación titulada «Galería Tassili (1970-1979)», que incluía una mera aproximación de nuestro objeto de estudio. Véase J. C. Aparicio Vega, «Galería Tassili (1970-1979)», en M. LlORDÉN Miñambres y J. M. MenéndeZ Llana, I Congreso de Estudios Asturianos, Oviedo, Real Instituto de Estudios Asturianos, 2007, vol. v, p. 289-299.

1. Consúltese el estudio completo sobre el sector de las galerías en la ciudad de Barcelona. Véase Jaume V. Oliveras (2012), Galerisme a Barcelona. 1877-2012: Descobrir, defensar, difondre l'art, Barcelona, Ajuntament de Barcelona y Art Barcelona Associació de Galeries.

Véase, además, una aproximación acerca del sector en Cataluña en C. Hueso i MuÑoz (2006), Aparadors d'art: Una aproximació a la història del galerisme a Catalunya. Dels inicis a la creació del Gremi de Galeries d'Art de Catalunya, Barcelona, Gremi de Galeries d'Art de Catalunya.

2. Esta firma, pionera en el sector, fue objeto de una cuidada monografía: M. MARAGALl (coord.) (2007), Sala Parés 130 años: 1877-2007, Barcelona, Sala Parés (Establiments Maragall).

3. «En España, hasta la década de los setenta no tuvo relevancia el mercado del arte vivo, pero a partir de entonces se han realizado esfuerzos ambiciosos y ha surgido una generación nueva de marchantes decididos a proyectarse en niveles altos de profesionalidad y en horizontes dilatados». Véase J. Marín-Medina (1993), «La importancia del galerista», $A B C$ Cultural, 74, Madrid (2 de abril), p. 27.

4. Consúltese E. Carmona (2005), «Las poéticas del arte nuevo y los círculos concéntricos de la Generación del 27: 1926-1931», en $L a$ pintura del 27, Madrid, Guillermo de Osma Galería [cat. exp.].

\section{J. Vidal Oliveras, Galerisme a} Barcelona..., op. cit., p. 50-66.

6. Para el caso de Madrid no existen estudios de conjunto de importancia. Véanse las aproximaciones siguientes: A. Fernández Polanco (1988), «Las Galerías de Arte en el Madrid de Postguerra: Su labor en la transformación del panorama artístico nacional», Villa de Madrid, 97-98 (marzo-abril), p. 5-27; P. Alarcó (1991), «Documentación / 2: Historia de las galerías de arte y de los espacios oficiales de exposiciones", en Del Surrealismo al Informalismo: Arte de los años 50 en Madrid, Madrid, Sala de Exposiciones de la Comunidad de Madrid, p. 204-263 [cat. exp.].

\section{J. Tusell y Á. Martínez Novi-} Llo (1991), Cincuenta años de Arte: Galería Biosca. 1940-1990, Madrid, Turner; L. Mercader (1997), «La Galería Biosca (1940-1959): De cómo Barcelona exporta la idea de galería de arte. De cómo Madrid difunde el arte catalán», en X. BRU DE SALA (dir.), Barcelona-Madrid. 1898-1998: Sintonías y Distancias, Barcelona, Institut d'Edicions de la Diputació de Barcelona / Centre de Cultura Contemporània de Barcelona, p. 206-217 [cat. exp.].

8. J. C. Aparicio Vega (2005), Galerias de arte en Asturias: espacios y promotores (19182005), Oviedo, Universidad de Oviedo, p. 254-258 [Tesis Doctoral Inédita].

9. Véase Tomás Seral y Casas: Un galerista en la posguerra, Madrid, Centro Cultural Conde Duque, 1998 [cat. exp.].

10. F. Calvo Serraller (coord.) (1992), Enciclopedia del arte español del Siglo XX. 2: El Contexto, Madrid, Mondadori, p. 140-141.

11. Carmina Abril era en realidad Carmen Díaz Herrero. Información facilitada por Carmen Benedet el 18 de diciembre de 2004. Véanse también J. Rubio (1985), «Ha muerto Carmina Abril, algo más que una galería», $A B C$, Madrid (17 de octubre), p. 53 [información procedente del Archivo Benedet]; F. Calvo Serraller (coord.), Enciclopedia del arte español..., op. cit., p. 109; A. Fernández Polanco, «Las Galerías...», art. cit., p. 14 y 382, y P. Alarcó, «Historia de...», op. cit., p. 240.

12. A. Martí (s. f.), «Artistas exclusivos", Folleto informativo, Madrid, Sala Neblí.

13. J. Vidal Oliveras, Galerisme a Barcelona..., op. cit., p. 67-75.

14. Se puede encontrar una aproximación a la trayectoria de esta galerista en XXV Aniversario de la Galería Juana Mordó.1964-1989, Madrid, Círculo de Bellas Artes, 1989 [cat. exp.].
15. F. Calvo Serraller (coord.), Enciclopedia del arte español..., op. cit., p. 135.

16. Sobre la trayectoria de la galerista, véase J. C. ApARICIO Vega (2018), «Carmen Benedet: una galerista pionera en el circuito español de los años sesenta», Anales de Historia del Arte, 18, p. 395-416.

17. A. Lucas (2014), «Lo que el vivir alberga (Conversaciones con Soledad Lorenzo)», en Soledad Lorenzo: Una vida con el arte, Madrid, Fundación Arte y Mecenazgo, p. 31-32 y 37-38.

18. B. SÁnchez Berciano e I. GóMEZ DE LiAÑo (1999), Fefa Seiquer, Madrid, Círculo de Bellas Artes.

19. F. Calvo Serraller (coord.), Enciclopedia del arte español..., op. cit., p. 396-397.

20. F. Carpio (2004), «Cumpleaños feliz», Blanco y Negro Cultural, 646 (12 de junio), p. 28.

21. J. C. Aparicio Vega (2018), «El nacimiento del circuito artístico moderno de Oviedo (España): la Tertulia Naranco (1953)», Tsantsa Revista de Investigaciones Artísticas, 6, p. 223-247.

22. J. C. Aparicio Vega (2005),

Galerias de..., op. cit., p. 281-316 [Tesis Doctoral Inédita].

\section{Ibídem, p. 316-322.}

24. Sobre este asunto, véase nuestro trabajo J. C. ApARICIO Vega (2012), «Coleccionismo artístico en el antiguo Palacio Provincial de Oviedo (1910-2010)», ASRI. Arte y Sociedad. Revista de Investigación, 1.

25. Consúltense más informaciones acerca de la institución en A. MARTín García (1978), Museo de Gijón, Gijón, Ayuntamiento de Gijón.

26. Así, la programación del nuevo museo ovetense reflejó en su primera etapa, comprendida entre los años 1980 y 1994, una clara apuesta por el arte contemporáneo. Se presentaron exposiciones de autores en activo residentes o vinculados a Asturias, y en no pocos casos eran coincidentes con la nómina de expositores de la ya extinta galería Tassili. Véase el listado completo en el Catálogo de las Exposiciones de Arte Contemporáneo (1980-1994), Oviedo, Museo de Bellas Artes de Asturias, 1995. Tras esto, la institución se concentró especialmente y durante largos años en conformar un destacado fondo de arte antiguo. 
27. Para el estudio sobre esta galería de arte hemos contado con el archivo económico de la firma, raramente puesto a disposición de los investigadores, además de con los testimonios directos del galerista y del interiorista que diseñó la sala.

28. En esta céntrica vía urbana y en otras zonas próximas hubo otras iniciativas relacionadas con la exhibición de obras de arte, como Casa Angelín, la cava del café Rívoli y la Sala Cristamol.

29. Información facilitada por J. A. Fernández-Castañón.

30. Esta elección fue tomada durante una reunión mantenida entre el fundador de Tassili y varios artistas locales en el desaparecido restaurante Marchica, de Oviedo. Información facilitada por el galerista durante la entrevista mantenida el día 13 de marzo de 2003.

31. M. a S. Álvarez Martínez (1980), «Crónica de exposiciones 1979», Liño, 1, p. 155.

32. Véase la entrada dedicada a J. A. Fernández-Castañón en AA.VV. (2000), Quién es quién en el Principado de Asturias: 1000 Protagonistas de la vida regional, Oviedo, Nobel, p. 90-91.

33. José Antonio Fernández-Castañón Carrasco se licenció en Derecho en la Universidad de Oviedo y también estudió Periodismo en Madrid. Así, escribió en las páginas literarias de Región. También fue redactor de arte en Asturias Diario Regional y fundó, conjuntamente con Emilio Marcos, la editorial Biblioteca Popular Asturiana en 1978. Véase Quién es quién en el Principado de Asturias: 1000 protagonistas de la vida regional, Oviedo, Nobel, 2000, p. 90 y 91. Información ampliada por el galerista durante la entrevista mantenida el día 13 de marzo de 2003.

34. Fue sustituido desde marzo de 1970 por el artista José María Navascués y, posteriormente, ocupó su puesto el crítico Jesús Villa Pastur.

35. J. A. Castañón (1969), «¿Arte para el Consumo?», Asturias Semanal, 9, Oviedo (19 de julio), p. 51.

36. J. A. Castañón (1969), «G.R.A.V. Grupo de Investigación del Arte Visual», Asturias Semanal, 15, Oviedo (30 de agosto), p. 49. En esta ocasión este autor reflexionó acerca del GRAV, «grupo de artistas unidos» desde la capital francesa por «la investigación del arte visual». En este sentido, conviene recordar que la formación universitaria de Castañón se completó con estancias en Francia y en el Reino Unido en los años sesenta.

37. J. A. Fernández-Castañón (1970), «La Dictadura Patronal del Marchand», Asturias Semanal, 43, Oviedo (14 de marzo), p. 51.

38. Asimismo, la empresa no contrató a ningún empleado. Información facilitada por el galerista durante la entrevista mantenida en su domicilio ovetense el día 13 de marzo de 2003.

39. La nueva construcción sigue la pauta en cuanto a su alineación determinada a partir de 1929 , con la construcción de la Casa Blanca de la misma calle, diseñada por el Estudio Busto.

40. Archivo Municipal de Oviedo (AMO), expediente 12,7,105,8, f. 2 y s.

41. Antes, en ese mismo solar, había una residencia unifamiliar conocida como el Chalet de Encarnación. Gran parte del centro de la ciudad hubo de ser reedificado de nuevo apenas cuatro décadas después de haber sido conformado, debido a los daños ocasionados durante las trágicas jornadas revolucionarias de octubre de 1934. La zona en que se ubica la galería estuvo definida por varias manzanas de domicilios unifamiliares con jardín, que se sustituyeron por bloques plurifamiliares dedicados a viviendas de alquiler.

\section{AMO, expediente $882 / 1935$,} f. 4 .

43. AMO, expediente 3,1,2,24, f. 10.

44. AMO, expediente $12,7,105,8$. Interpretación a partir de la planimetría contenida en el expediente $\mathrm{y}$ de las indicaciones aportadas por el galerista.

El local expositivo adaptó tres piezas de la casa dispuestas en batería. El espacio de la sala era el que permitiría dar acceso a la sala mediante el vestíbulo que comunica con la zona de ascensor y escalera. Véase también AMO, expediente 1217-971134, f. 34 y 41.

45. AMO, expediente $3,1,2,24$, f. $8 \mathrm{v}$.

46. Ibídem, f. 1 .

47. Información facilitada por el galerista durante la entrevista mantenida el día 13 de marzo de 2003.

48. Se convirtió en despacho de abogados inicialmente y actualmente es la sede de una aseguradora.

49. Información facilitada por José Antonio Menéndez Hevia durante la entrevista mantenida en su estudio de Gijón el 11 de julio de 2003.

50. En el primer rellano una puerta conducía directamente al recinto de la galería. Ídem.

51. AMO, expediente 1217-

971134, f. 34 y 41.

52. AMO, expediente $12,7,105,8$. Interpretación a partir de la planimetría contenida en el expediente $\mathrm{y}$ de las indicaciones aportadas por el galerista.

53. No se conserva el proyecto de la galería. Informaciones facilitadas por José Antonio Menéndez Hevia (Gijón, 11 de julio de 2003).

54. Sobre este profesional del interiorismo, consúltese A. Puente Toraño, «José Antonio Menéndez Hevia: Diseñador, arquitecto, interiorista y constructor especializado», en A. M. ${ }^{a}$ Fernández García (coord.) (2012), Decoración de interiores: Firmas, casas comerciales $y$ diseño en Asturias. 1880-1900, Oviedo, Septem Ediciones, p. 173-217.

55. Información facilitada por José Antonio Menéndez Hevia durante la entrevista mantenida en su estudio de Gijón el 11 de julio de 2003.

56. Ibídem.

57. Los módulos de escayola favorecieron que se pudiera controlar adecuadamente la luz natural sin incidir sobre los cuadros, ya que esta lo hacía sobre los paños frontales.

Los finos cierres de las ventanas instalados por la firma Díher eran de fabricación italiana. Información facilitada por el galerista durante la entrevista mantenida en su domicilio ovetense el día 13 de marzo de 2003 y por José Antonio Menéndez Hevia en su estudio de Gijón el 11 de julio de 2003.

58. Información facilitada por el galerista durante la entrevista mantenida en su domicilio ovetense el día 13 de marzo de 2003.

59. Se colocaron lámparas cálidas y puntos de control de la misma cualidad. Información aportada por José Antonio Menéndez Hevia durante la entrevista mantenida en su estudio de Gijón el 11 de julio de 2003. 
60. Ibídem.

61. Sobre este asunto, véase nuestro trabajo J. C. ApAricio VEgA (2019), «El mobiliario de las galerías de arte en Oviedo (19791996)», en R. J. Payo Hernanz, E. Martín Martínez de Simón, J. MATESANZ DEL BARRio y M $\mathrm{M}^{\mathrm{a}}$ José ZAPARAÍn YÁÑEZ (eds.), Vestir la arquitectura. XII Congreso Nacional de Historia del Arte, Burgos, vol. 2, p. 1694-1702.

62. Datos facilitados por J. A. Fernández-Castañón el 13 de marzo de 2003.

63. Información del galerista (Oviedo, 13 de marzo de 2003).

64. Entre sus pretensiones estaba la de «superar en lo posible la incomunicación que se da entre este arte nuevo y los grupos sociales de la vida española. Difundir el arte. Lo ideal tal vez sería llevar las exposiciones al encuentro de la gente». Igualmente, proclamaba su intención de «luchar contra el alza de los precios». Castañón se proponía que el público entrase en la sala argumentando que "Yo invito a todos los que quieran visitarla, como si se tratase de un museo gratuito». Véase Asturias Semanal, 45, Oviedo (28 de marzo de 1970), p. 51.

65. Véanse La Nueva España, Oviedo (21 de marzo de 1970), y La Voz de Asturias, Oviedo (1 de abril de 1970).

66. Véase el díptico de invitación a la exposición: Amparo Cores, Galería Tassili, Oviedo, del 1 al 14 de abril de 1970.

67. Información facilitada por el galerista durante la entrevista mantenida en su domicilio ovetense el día 13 de marzo de 2003.

68. Para este estudio se ha contado con la consulta del extenso documento titulado Galería Tassili: Índice de Exposiciones [Índice de Exposiciones, Galería Tassili, Oviedo]. Se trata de un cuaderno manuscrito de 219 folios sin paginar en que se da cuenta de todas las exposiciones de la galería y de las de Arte Mon. Además, contiene todos los movimientos de venta efectuados por J. A. Fernández-Castañón entre 1970 y 1979, incluidos los del nutrido fondo de galería. Las anotaciones comienzan a partir de la muestra número 1, abierta el 1 de abril de 1970, y llegan hasta la número 143, clausurada el 19 de junio de 1979. Todas las informaciones referidas a movimientos de ventas y las fechas de las exposiciones provienen de este documento.

69. Índice de Exposiciones, Galería Tassili, Oviedo.

70. Información facilitada por el galerista durante la entrevista mantenida en su domicilio ovetense el día 13 de marzo de 2003.

\section{Ibídem.}

72. Véanse «Amparo Cores inaugura hoy la nueva galería de arte Tassili», La Nueva España, Oviedo (1 de abril de 1970); M. Codax (1970), «Amparo Cores inauguró la Galería Tassili», Asturias Semanal, 47, Oviedo (11 de abril), p. 51, y G. G. Alcalde y J. Vélez (1970), «Amparo Cores: La revelación de una veterana», La Nueva España, Oviedo (3 de abril), p. 9.

Los precios estaban entre las 10.000 pesetas y las 45.000 pesetas. Expuso principalmente obra pequeña.

73. Se trataba de una selección de sus dibujos a color y tintas que fue expuesta entre el 17 y el 29 de abril de 1970.

74. La exposición tuvo lugar entre el 30 de abril y el 15 de mayo de 1970.

75. La muestra se celebró entre el 16 y el 31 de mayo de 1970.

76. Véase la tarjeta de la exposición, celebrada entre el 17 y el 30 de junio de 1970.

77. Expuso entre el 15 y el 30 de septiembre de 1970.

\section{Ibídem.}

79. Este artista leonés expuso sus óleos sobre madera y guaches entre el 30 de octubre y el 20 de noviembre de 1970 .

80. El hermano del fundador de la galería gijonesa Altamira ocupó la sala entre el 21 de noviembre y el 7 de diciembre de 1970.

81. Tanto Moya como González expusieron en Tassili en diciembre de 1970.

82. La muestra tuvo lugar entre el 20 de enero y el 6 de febrero de 1971.

83. Expuso en febrero de 1971.

84. Villar muestra sus acrílicos sobre lienzo y madera y sus maquetas entre el 24 de febrero y el 12 de marzo de 1971 . Se trataba en realidad de una instalación. Información ampliada por el galerista durante la entrevista mantenida en su domicilio ovetense el día 13 de marzo de 2003.

85. Carlos Casariego expuso entre el 14 y el 28 de abril de 1971 un conjunto de obras hechas en base a pintura plástica sobre lienzo.

86. Husen mostró sus dotes de aguafortista entre el 4 y el 20 de mayo de 1971.

87. El 22 de septiembre Humberto mostraba sus óleos sobre madera, tela y papel en una muestra que se cerraría el 10 de octubre de 1971.

88. Bartolomé expuso sus litografías romanas entre el 2 y el 17 de octubre de 1971.

89. Casado expuso sus guaches entre el 20 de octubre y el 3 de noviembre de 1971.

90. Jaime Herrero expuso óleos sobre lienzo y tintas entre el 4 y el 17 de noviembre de 1971.

91. Manolo Calvo expuso serigrafías, acrílicos sobre tela y collage en noviembre de 1971, pero no se consignó venta alguna de su obra.

92. Úrculo presentó 7 pinturas y 2 tapices de desnudos femeninos. Las piezas tenían una valoración económica de entre 25.000 pesetas y 100.000 pesetas. Se vendieron unas cuantas serigrafías y hasta un guache.

Véase también G. G. Alcalde (1971), «Úrculo: ¿Erotismo o Neorromanticismo?», La Nueva España, Oviedo (3 de diciembre); J. A. Cepeda (1971), «Pinturas y Tapices de Eduardo Úrculo», Región, Oviedo, (4 de diciembre); C. R. (1971), «Eduardo Úrculo: Me interesa objetivar el cuadro", sin fuente (2 de diciembre); V. Alperi (1970), «Algunas notas sobre el pintor Eduardo Úrculo», Región, Oviedo (5 de diciembre).

93. La exposición se celebró entre el 20 de diciembre de 1971 y el 15 de enero de 1972. El banquero ovetense Ignacio Herrero compró una de las obras más caras.

94. J. Villa Pastur, «Los Grabados de José Ortega», La Voz de Asturias, Oviedo (28 de diciembre).

\section{Esta importante muestra} transcurrió entre el 23 de marzo y el 4 de abril de 1971 y tan solo se vendió una escultura de Alba a la firma Díher por 40.000 pesetas.

«Después de un año de conversaciones ha nacido el grupo artístico Astur 71», El Comercio, Gijón (21 de marzo de 1971). Las 
reuniones se celebraron en forma de «tertulia volante», tanto en los estudios de Alejandro Mieres (Gijón) y en el de María Antonia Salomé (Pola de Lena) como en el de Alba.

96. Sirvan como ejemplo: Julio FuENTE (1971), «Astur 71, la gran esperanza artística», Región, Oviedo (25 de marzo); Jesús Villa Pastur (1971), «Pintura: Astur 71», La Voz de Asturias, Oviedo (28 de marzo).

97. La exposición se celebró entre el 3 y el 15 de febrero de 1972.

98. La muestra se presentó entre el 19 y el 26 de febrero de 1972.

Ese mismo año otros pintores locales, algunos de menor interés, como Manuel García Linares y María Luisa Valdés, ocuparon la galería y aumentaron las ventas. De esta última se vendieron 18 obras.

Humberto también expuso entre el 16 y el 30 de noviembre del mismo año.

99. Orcajo expuso entre el 11 y el 24 de marzo de 1972 y vendió una obra.

100. Esta muestra programada entre el 7 y el 20 de abril de 1972 trajo a Oviedo sus óleos sobre tela, acuarelas y ceras. Se consignó la venta de siete obras.

101. Equipo Crónica expuso entre el 27 de abril y el 16 de mayo de 1972. Se vendieron nueve obras. Véase también el cuidado díptico de la exposición.

102. Véase el catálogo de mano de la exposición Linares, Galería Tassili, Oviedo, del 28 de febrero al 10 de marzo de 1972 y el cartel folleto de la exposición Linares, Galería Tassili, Oviedo, del 14 al 25 de marzo de 1974.

103. La exposición número 33 de Tassili estuvo dedicada a Ibarrola, entre el 17 y el 31 de mayo de 1972, quien trajo a Oviedo óleos y obra gráfica. Vendió 96 grabados por un total de 12.000 pesetas.

Véase la tarjeta de la exposición Agustín Ibarrola, Galería Tassili, Oviedo, del 17 al 31 de mayo de 1972. La galería editó bajo idéntico título en que se incluye un extenso texto del artista con el enunciado de Apuntes orientados a explicar algunos de los aspectos de mi pintura que considero han sido menos comprendidos. Es clara la intención de la galería por promover el verdadero arte y además su esfuerzo por hacerlo inteligible, algo que enlazaría con la misma voluntad que había expresado Castañón desde las páginas de arte de Asturias Semanal.
Además, en 1974, este creador vasco repitió presentación en este nuevo espacio expositivo ovetense. Véase el folleto Exposición de Obras de Ibarrola, Galería Tassili, Oviedo, desde el 17 de abril de 1974. Esta exposición número 63 de la galería se celebró entre el 17 de abril y el 30 de abril de 1974. Se vendieron 54 grabados por un total de 10.800 pesetas.

104. Tuvo lugar entre el 4 y el 15 de diciembre de 1972.

105. «Obra gráfica de Elías G. Benavides en la galería Tassili», La Nueva España, Oviedo (3 de diciembre de 1972).

106. Expuesto entre el 16 y el 27 de diciembre de 1972.

107. Fue programada entre el 17 y el 31 de enero de 1973 . Se vendieron tres obras de Aurelio Suárez, una por 25.000 y las otras dos por 28.000 pesetas cada una, además de otras tantas de Úrculo, aunque por una cotización más baja. Véase también la tarjeta de la exposición Tres Pintores Asturianos, Galería Tassili, Oviedo, del 17 al 31 de enero de 1973.

108. Véase la tarjeta de la exposición 11 Artistas Asturianos, Galería Tassili, Oviedo, del 18 al 30 de junio de 1973.

109. R. Rodríguez expuso sus óleos y acrílicos sobre madera entre el 20 de febrero y el 3 de marzo de 1973. Fue un éxito de ventas (15 obras) e incluso la Delegación de Juventud compró obra.

110. Armando Pedrosa expuso entre el 5 y el 16 de mayo de 1973, pero entonces no vendió nada.

111. Reyes Díaz expuso óleos y dibujos entre el 20 de noviembre y el 3 de diciembre de 1973.

\section{José Santamarina expuso} sus collages entre el 4 y el 16 de diciembre de 1973. Véase el cartel folleto de la exposición José Santamarina: Obra Gráfica, Galería Tassili, Oviedo, del 4 al 16 de diciembre de 1973. Fue espectacular el delicado cartel anunciador diseñado para la caja expositor de la fachada de la galería.

113. Las serigrafías gallegas se vendieron muy bien entre el $17 \mathrm{y}$ el 28 de mayo de 1973, un total de 98 por 82.200 pesetas.

114. Véase la publicación editada por la galería.
115. Véase el cartel de la exposición Manolo Millares: Obra Gráfica, Oviedo, Galería Tassili, del 9 al 21 de octubre de 1973. Este artista había muerto en Madrid en agosto de 1972 .

116. La exposición se celebró entre el 3 y el 14 de abril de 1973 .

117. La muestra se desarrolló entre el 23 de octubre y el 3 de noviembre de 1973.

118. Véase el impreso de la exposición Marixa: Óleos y tintas, Oviedo, Galería Tassili, del 17 al 30 de diciembre de 1973

119. Véase el impreso de la exposición Emilio Sala y Francés, Oviedo, Galería Tassili, del 5 al 16 de enero de 1974. Se vendió una decena de obras.

120. La exposición se celebró entre el 21 de mayo y el 4 de junio de 1974.

121. La exposición tuvo lugar en junio de 1974.

122. La exposición fue presentada entre el 9 y el 22 de diciembre de 1974 y no se vendió nada.

123. Alejandro Mieres abrió la temporada 1974-1975 con una muestra de dibujos y óleos, de los que vendió hasta 9 piezas y tuvo lugar entre el 8 y el 21 de octubre de 1974.

124. Adolfo Bartolomé expuso entre el 15 de noviembre y el 4 de diciembre de 1974.

125. Rubio expuso sus óleos, ceras y dibujos a precios muy económicos, lo que se tradujo en un buen número de obras vendidas entre el 2 y el 14 de noviembre de 1974.

126. La exposición se celebró el mismo año en que lo haría en Bélgica y Alemania. Repitió el año antes de desaparecer trágicamente, después del Art Basel (1977). Véanse el cartel de la exposición Navascués: Esculturas, Galería Tassili, Oviedo, del 3 al 17 de mayo de 1974, y el díptico Navascués, Galería Tassili, Oviedo, del 11 al 25 de octubre de 1978 , así como también el cuidado catálogo de mano de la exposición que editó la galería Tassili.

127. Ortega expuso entre diciembre de 1974 y enero de 1975 .

128. Sus óleos y acuarelas se exhibieron entre el 18 y el 31 de enero de 1975.

129. Castillo expuso entre el 1 y el 13 de febrero de 1975. 
130. Salvador Montesa expuso entre el 6 y el 21 de marzo de 1975.

131. La exposición que estaba previsto mantener abierta entre el 8 y el 22 de abril de 1975 se prorrogó hasta el día 30. Consúltese el cartel de la exposición La Vaca: Úrculo, Galería Tassili, Oviedo, del 8 al 22 de abril de 1975.

132. Este autor expuso entre el 14 de febrero y el 3 de marzo de 1975.

133. Véanse los impresos de sus exposiciones: Lombardía, Galería Tassili, Oviedo, del 23 de mayo al 6 de junio de 1975; Miguel Ángel Lombardia: Obra reciente, Galería Tassili, Oviedo, del 28 de abril al 12 de mayo de 1977, y Miguel Ángel Lombardía: Esculturas. 1975-1978, Galería Tassili, Oviedo, del 28 de abril al 10 de mayo de 1978.

134. Sanjurjo expuso entre el 25 de octubre y el 9 de noviembre de 1975 sus guaches y óleos sobre madera. Esta muestra resultó ser otro considerable éxito económico.

135. Pérez de Castro expuso en Tassili sus óleos sobre lienzo entre el 25 de noviembre y el 6 de diciembre de 1975. Una de las piezas expuestas fue adquirida por la galería Módena, de Madrid.

136. Cecchini mostró sus obras ejecutadas en técnica mixta sobre formica entre el 9 y el 22 de diciembre de 1975.

137. Vicente Iglesias presentó sus dibujos entre el 23 de diciembre de 1975 y el 12 de enero de 1976.

138. Diego Moya expuso entre el 6 y el 20 de mayo de 1975 sus esculturas y múltiples, tres de los cuales fueron adquiridos por el Colegio de Arquitectos.

139. Manuel Ayllón presentó sus esculturas entre el 4 y el 16 de febrero de 1976.

140. Ramón Rodríguez expuso entre el 18 de febrero y el 2 de marzo de 1976.

141. García Benavides volvió a la sala entre el 20 de octubre y el 3 de noviembre de 1976. Véase el díptico de la exposición Elías G. Benavides, Galería Tassili, Oviedo, del 20 de octubre al 3 de noviembre de 1976.

142. Humberto ocupó la sala entre el 2 y el 14 de diciembre de 1976.

143. José Luis Fernández expuso entre el 16 y el 30 de diciembre de 1976.
144. Se presentaron conjuntamente entre el 4 y el 20 de junio de 1976.

145. José Paredes expuso sus acuarelas entre el 5 y el 18 de octubre de 1976.

146. Ibídem. Véase también el impreso de la exposición Legazpi, Galería Tassili, Oviedo, del 5 al 18 de mayo de 1976.

147. Tuvo lugar entre el 21 de abril y el 4 de mayo de 1976.

148. La exposición transcurrió entre el 3 y el 16 de marzo de 1976.

149. Higinio del Valle expuso entre el 18 de mayo y el 2 de junio de 1976.

150. Entre el 17 y el 30 de marzo de 1976, Sierra ofreció al público ovetense un conjunto formado por óleos, guaches y dibujos cuyos precios oscilaban entre las $10.000 \mathrm{y}$ las 125.000 pesetas.

El planteamiento expositivo fue muy novedoso. Incluso había trabajos colgados del techo y hojas por el suelo. Información facilitada por el galerista durante la entrevista mantenida en su domicilio ovetense el día 13 de marzo de 2003.

151. Véase la tarjeta de la exposición Aurelio Suárez / Orlando Pelayo / Eduardo Úrculo, Galería Tassili, Oviedo, del 23 de septiembre al 4 de octubre de 1976 .

152. Este prestigioso autor catalán expuso aguafuertes y litografías realizados mediante la técnica del collage entre el 12 y el 24 de enero de 1977.

153. Ángel Guache expuso entre el 14 y el 27 de abril de 1977.

154. Miguel Ángel Lombardía mostró sus collages, óleos y dibujos entre el 28 de abril y el 12 de mayo de 1977.

155. Alejandro Mieres expuso sus óleos sobre madera y dibujos entre el 4 y el 17 de octubre de 1977. Véase el díptico de la exposición Mieres: Óleos y Tintas, Galería Tassili, Oviedo, del 4 al 17 de octubre de 1977.

156. Bernardo Sanjurjo expuso entre el 16 y el 29 de noviembre de 1977 , donde vendió una docena de obras.

157. José Santamarina presentó sus collages (cartulinas superpuestas) entre el 30 de noviembre y el 13 de diciembre de 1977 . Véase el original cartel folleto de la exposición José Santamarina, Galería Tassili, Oviedo, del 30 de noviembre al 13 de diciembre de 1977.
158. Paz Vial expuso entre el 21 de febrero y el 4 de marzo de 1977.

159. Kiker ocupó el local de la calle Uría con sus óleos entre el 5 y el 18 de marzo de 1977.

160. Tuvo lugar entre el 3 y el 17 de junio de 1977, pero tan solo se vendió una pieza.

161. Agulló expuso sus óleos sobre lienzo y sus dibujos entre el 18 y el 29 de octubre de 1977.

162. Eduardo Gruber expuso entre el 2 y el 14 de noviembre de 1977.

163. Véase la tarjeta de la exposición Pintores Españoles en París, Galería Tassili, Oviedo, del 7 al 20 de febrero de 1977. Se pudo ver el trabajo de Bores, Clavé, Cossío, Domínguez, Flores, De la Serna, Grau Sala, Lagar, Parra, Peinado, Pelayo, Togores y Viñes. Los óleos alcanzaban un valor variable entre 60.000 y 1.500 .000 pesetas.

164. Se celebró entre el 24 de diciembre de 1977 y el 5 de enero de 1978.

165. Úrculo expuso otra vez entre el 10 y el 24 de mayo de 1978 y vendió cuatro trabajos. Véase el cartel de la exposición Pinturas, dibujos y serigrafías de Úrculo, Galería Tassili, Oviedo, mayo de 1978.

166. Cores volvió a exponer entre el 6 y el 21 de marzo de 1978 y cosechó éxito económico, pues se vendieron 16 trabajos.

Igualmente, repitieron ante el público de Tassili Lombardía, Ramón Rodríguez y Legazpi, entre otros. Melquíades Álvarez y Pelayo Ortega expusieron también, pero por separado. H.A. Colectivo también expuso en junio de 1978.

167. Vallina expuso entre el 11 y el 22 de enero de 1978.

168. Acosta presentó su obra reciente entre el 26 de enero y el 7 de febrero de 1978.

169. Muñiz exhibió un conjunto de dibujos, acrílicos y obras sobre madera entre el 26 de mayo y el 8 de junio de 1978.

170. Amador protagonizó una muestra entre el 18 y el 28 de febrero de 1978. En aquella ocasión se pudieron ver sus dibujos, serigrafías y esculturas.

171. Guillermo Basagoiti presentó sus esculturas y relieves entre el 9 y el 21 de febrero de 1978. 
172. José Nava Iglesias expuso sus esculturas en madera, piedra, talco y bronce entre el 25 de enero y el 7 de febrero de 1978.

173. Navascués presentó por última vez su trabajo entre el 11 y el 24 de octubre de 1978. Se vendieron 7 obras por 350.000 pesetas.

174. Ramón Prendes expuso sus óleos sobre papel y sobre madera entre el 8 y el 21 de febrero de 1979.

175. Pepa Osorio exhibió obras ejecutadas en técnica mixta sobre papel entre el 9 y el 22 de marzo de 1979 y tampoco hubo ventas. También expusieron de nuevo Paredes, Humberto, Sierra, Iglesias y Vial.

176. La exposición final se celebró entre el 31 de mayo y el 19 de junio de 1979. Vendió dos obras en bronce por 40.000 pesetas cada una.

177. Información facilitada por el galerista durante la entrevista mantenida en su domicilio ovetense el día 13 de marzo de 2003.

178. Mordó facilitó la muestra de Equipo Crónica.

179. En esta galería madrileña adquirió Castañón obra de Álvaro Delgado, Luis García Ochoa, Andrés José Cillero y Manolo Calvo.

180. La galería Punto surtía a la sala ovetense de obra gráfica y serigrafías de artistas como Canogar y Barjola. Información facilitada por el galerista durante la entrevista mantenida en su domicilio ovetense el día 13 de marzo de 2003.

Esta firma fundada en Valencia en 1972 estuvo a cargo de Miguel Agrait Colomer (1919-2010), recientemente objeto de una muestra homenaje acompañada de un catálogo en que se recuerda su labor. Véase Sueño y realidad, un bomenaje a Miguel Agraï, Galería Punto y Fundación Chirivella Soriano, Valencia, 2012 [cat. exp.].

181. Polígrafa cedió la muestra gráfica de Guinovart.

182. Véase el impreso de la exposición Jaime Herrero, Sala Provincia, León, del 1 al 15 de diciembre de 1971.

183. Información facilitada por el galerista durante la entrevista mantenida en su domicilio ovetense el día 13 de marzo de 2003.

184. La galería era un foco izquierdista en la ciudad de Oviedo durante la dictadura franquista.
Paloma Uría, esposa del galerista, era miembro del PCE.

185. Tassili abrió el mismo año que Egam (Madrid) y Juana de Aizpuru (Sevilla y Madrid).

Véanse F. Calvo Serraller (coord.), Enciclopedia del..., op. cit., p. 77-78 y 136-137; M. LORENTE (1995), «Bodas de plata con el arte», $A B C$ Cultural, 215 (noviembre), p. 38, <http://www. juanadeaizpuru.com $>$ [Consulta: 12 de agosto de 2009].

186. Cuando los funcionarios de la Brigada Político-Social preguntaban al galerista los títulos de los cuadros, este respondía dando un número y el precio de la obra. Información facilitada por el galerista durante la entrevista mantenida en su domicilio ovetense el día 13 de marzo de 2003.

187. Agradezco la consulta de esta carta fechada en Oviedo a 2 de abril de 1972 y facilitada por el galerista para este estudio.

188. Información facilitada por el galerista durante la entrevista mantenida en su domicilio ovetense el día 13 de marzo de 2003.

189. J. Barón (1996), «La Pintura en Asturias entre 1960 y 1996», en Pintores Asturianos nacidos en las décadas 40 y 50, Oviedo, Consejería de Cultura del Principado de Asturias, p. 26 [cat. exp.].

Alejandro Mieres (Astudillo,

Palencia, 1927 - Gijón, 2018), José María Navascués (Madrid, 1934 - Oviedo, 1979), Manuel Arenas (Oviedo, 1949 - Gijón, 2020), Mariano García Ciagar (León, 1936), Fernando Alba (La Folguerosa, 1944) y M. a Antonia Salomé (Pola de Lena, 1934-2008) integraron Astur. 71. Véase el catálogo de mano de la exposición Astur 71, Galería Tassili, Oviedo, del 23 de marzo al 4 de abril de 1971.

190. Véanse El Comercio, Gijón (21 de marzo de 1971), y La Nueva España, Oviedo (23 de marzo de 1971).

191. A principios de los años setenta el galerista residía en Gijón. Información facilitada por el galerista durante la entrevista mantenida en su domicilio ovetense el día 13 de marzo de 2003.

192. Véase el texto de presentación que José Antonio FernándezCastañón incluyó en el folleto de la exposición Astur 71, Galería Tassili, Oviedo, del 23 de marzo al 4 de abril de 1971. En el ejemplar que nos facilitó el galerista para su estudio el texto aparece firmado por él mismo. Participaron Alba, Mariantonia Salomé, Mieres, Arenas, Mariano y Navascués. Este último expresó en la publicación lo que sigue: «Pienso que el arte consiste en utilizar con destreza cualquier herramienta contundente: el lápiz, el garrote, la palabra, el láser, la ética, el pincel, las matemáticas, la mirada o el dos piezas; lo demás es estudio de mercados».

193. Consúltese también J. Puente (1971), «Astur 71, La gran esperanza artística», en Región, Oviedo (25 de marzo de 1971), y J. Villa Pastur (1971), «Astur 71», La Voz de Asturias, Oviedo (28 de marzo). La muestra supuso la apertura pública de las actividades del grupo experimental.

194. Información facilitada por el galerista durante la entrevista mantenida en su domicilio ovetense el día 13 de marzo de 2003.

\section{Ibídem.}

196. Ibídem. Véase también la tarjeta impresa de Tassili con el motivo facilitada por el galerista.

197. Véase el tríptico de la exposición Creando Imagen. Elías E Santamarina. Diseño y Comunicación, Caja de Asturias, OviedoAvilés-Mieres-La Felguera, del 3 de mayo al 19 de noviembre de 1994.

198. Información facilitada por Javier Barón el día 11 de julio de 2003.

199. Información del galerista (Oviedo, 13 de marzo de 2003).

200. Ibídem.

201. Véase Guache. Apariciones, Biblioteca Popular Asturiana / Galería Tassili, Oviedo, 1979.

202. Información facilitada por el galerista durante la entrevista mantenida en su domicilio ovetense el día 13 de marzo de 2003.

203. Agradezco a José Antonio Fernández-Castañón la cesión para este estudio de una carta remitida por el Subdelegado de la Inspección de Hacienda al responsable de la galería y datado a 29 de marzo de 1978 y el formulario referido, titulado Datos a facilitar por las salas de arte y exposiciones.

204. Fernández-Castañón también vendió ocasionalmente alguna pintura asturiana de cierta antigüedad, como la debida a la gijonesa Julia Alcayde, que salió del depósito en noviembre de 1977 por 10.000 
pesetas. Asimismo, en el otoño de 1976 vende dos trabajos del paisajista decimonónico Carlos de Haes por 1.000 pesetas cada uno, e incluso el crítico de arte Jesús Villa Pastur compró en enero de 1977 un grabado de Goya por la cantidad de 11.000 pesetas. También era habitual la comercialización de trabajos de Goico-Aguirre.

205. Información facilitada por el galerista durante la entrevista mantenida en su domicilio ovetense el día 13 de marzo de 2003.

206. Agradezco que el galerista haya facilitado para este estudio uno de esos recibos, transcrito literalmente.

\section{Ibídem.}

208. Información facilitada por el galerista durante la entrevista mantenida en su domicilio ovetense el día 13 de marzo de 2003.

\section{Ibídem.}

210. Ibídem. Es significativa la fidelidad de algunos compradores, muchos de ellos en práctica de profesiones liberales y del círculo social próximo a la propiedad, en buena medida progresista.

211. Información facilitada por el galerista durante la entrevista mantenida en su domicilio ovetense el día 13 de marzo de 2003.

212. Antonio Saura y los asturianos Úrculo, Mieres, Marixa, Ramón Rodríguez, Higinio del Valle, Orlando Pelayo y Bartolomé son algunos de los artistas de los que se compró obra en Tassili.

213. La colección propia del matrimonio formado por Paloma Uría y José Antonio Fernández-Castañón permite recorrer la historia de este comercio artístico. Información facilitada por el galerista durante la entrevista mantenida en su domicilio ovetense el día 13 de marzo de 2003.

214. El decorador e interiorista Jesús Quirós, cliente de Tassili, compró una obra de Alejandro Mieres por 28.000 pesetas en 1970 para Corner's Pub. También ingresaron algunas piezas en las oficinas de la firma de diseño e interiorismo de Menéndez Hevia, Díher, que eran adquiridas tanto en las exposiciones temporales como directamente del conjunto reunido por Castañón. Además, el autor de la sala colocó piezas de Tassili en otro negocio de su propiedad, Bureau 70, «una tienda de decoración y mobiliario» que abrió también en la capital. Véase además el artículo de P. Rubiera (2009), «José Antonio Menéndez Hevia: Todo estilo decorativo es interesante si el conjunto tiene armonía», La Nueva España, Oviedo (23 de mayo).

215. La Facultad de Económicas de la Universidad de Oviedo adquirió grabados en el depósito de la galería en marzo de 1977 por 45.000 pesetas.

216. Información facilitada por el galerista durante la entrevista mantenida en su domicilio ovetense el día 13 de marzo de 2003.

217. Véase la carta de comunicación remitida por la dirección de La Nueva España y fechada en Oviedo en el mes de febrero de 1974. Archivo Tassili, Oviedo. Información facilitada por el galerista durante la entrevista mantenida en su domicilio ovetense el día 13 de marzo de 2003.

218. En el archivo de la galería, consultado para nuestra investigación, se puede rastrear el permanente seguimiento de la actividad de la sala desde su misma apertura hasta su cierre. La anterior dedicación profesional del promotor al periodismo y su moderna propuesta fueron muy bien recibidas en términos generales y llenaban las páginas de la prensa local, incluidas las más cuidadas a cargo de los críticos de arte.

219. La tienda «se dedicará a la venta y exposición permanente de obra gráfica (grabado, litografía, serigrafías...). Es la primera de este tipo que se abre en Asturias y una de las pocas existentes en España». Véase el artículo de prensa sin fuente ni fecha conservado en el archivo del Museo de Bellas Artes bajo el título de «Se inauguró la sala ArteMon».

«En principio el espacio era solo para grabados de distintas épocas y autores», según anotaciones manuscritas del propietario. Archivo Tassili, Oviedo. ArteMon es una prolongación de Tassili y en ella se acomodaron obras de otras épocas que no encajaban en la línea artística de aquella.

220. La Voz de Asturias, Oviedo (14 de noviembre de 1974).

221. AMO, expediente 17,4,87,11, f. 14. Esta ya había sido solicitada por José Antonio Fernández-Castañón el 12 de diciembre de 1973. Véase también AMO, expediente 3866/73, f. 2 bis.

222. AMO, expediente 3866/73, f. 2 bis.

223. Datos facilitados por José Antonio Fernández-Castañón durante la entrevista mantenida en Oviedo el 19 de marzo de 2003.

224. AMO, expediente $5,5,50,12$, f. 1 .

225. Se hicieron media docena de exposiciones y el resto del tiempo se mostraba fondo de galería. Datos facilitados por José Antonio Fernández-Castañón durante la entrevista mantenida en Oviedo el 19 de marzo de 2003.

226. Véase el cartel folleto editado de la exposición Arte en Asturias: Grupo de artistas plásticos, ArteMon, Oviedo, del 14 al 30 de noviembre de 1974 . Véanse también la tarjeta de invitación de la exposición Grupo Arte en Asturias, ArteMon, Oviedo, del 14 al 30 de noviembre de 1974, y «Se inauguró la sala ArteMon», sin fuente y sin fecha.

227. Véase el artículo de prensa sin fuente y sin fecha conservado en el Museo de Bellas Artes bajo el título de «Se inauguró la sala ArteMon».

228. J. Barón (1985), «Diccionario de pintores y escultores», en Enciclopedia Temática de Asturias, V, Oviedo, Silverio Cañada, p. 282-283.

229. Información facilitada por José Antonio Fernández-Castañón durante la entrevista mantenida el 19 de marzo de 2003 en Oviedo. 
